\title{
Antioxidant Therapies for Alzheimer's Disease
}

\author{
Ye Feng and Xiaochuan Wang \\ Department of Pathophysiology, Key Laboratory of Neurological Disease of National Education Ministry, Tongji Medical College, \\ Huazhong University of Science and Technology, Wuhan 430030, China
}

Correspondence should be addressed to Xiaochuan Wang, wxch@mails.tjmu.edu.cn

Received 1 March 2012; Accepted 17 April 2012

Academic Editor: Madia Trujillo

Copyright ( $\odot 2012$ Y. Feng and X. Wang. This is an open access article distributed under the Creative Commons Attribution License, which permits unrestricted use, distribution, and reproduction in any medium, provided the original work is properly cited.

\begin{abstract}
Alzheimer's disease (AD) is the most common neurodegenerative disease featuring progressive impairments in memory, cognition, and behavior and ultimately leads to death. The histopathological changes of Alzheimer's disease include neuronal and synaptic loss, formation of extracellular senile plaques and intracellular neurofibrillary tangles in brain. Multiple lines of evidence indicate that oxidative stress not only strongly participates in an early stage of Alzheimer's disease prior to cytopathology, but plays an important role in inducing and activating multiple cell signaling pathways that contribute to the lesion formations of toxic substances and then promotes the development of Alzheimer's disease. Many years of studies show that antioxidant therapies have enjoyed general success in preclinical studies. Therefore, this paper mainly focuses on the recent developments of common used antioxidant therapies for Alzheimer's disease and thus provides indications for future potential antioxidant therapeutic strategies of neurodegenerative diseases.
\end{abstract}

\section{Introduction}

Alzheimer's disease $(\mathrm{AD})$ is one of the most common neurodegenerative disorders that frequently cause dementia and affect the middle- to old-aged individuals, approximately one in four individuals over the age of 85 . Dementia is characterized by a progressive cognitive decline leading to social or occupational disability. However, AD must be differentiated from other causes of dementia including vascular dementia, dementia with Lewy bodies, Parkinson's disease with dementia, frontotemporal dementia, and reversible dementias [1]. AD has multiple etiological factors including genetics, environmental factors, and general lifestyles [2], and its pathophysiological hallmarks include extracellular $\beta$-amyloid protein $(A \beta)$ deposition in the forms of senile plaques and intracellular deposits of the microtubuleassociated protein tau as neurofibrillary tangles (NFTs) in the $\mathrm{AD}$ brains. When the first case of a 51-year-old woman who presented with a relatively rapidly deteriorating memory along with psychiatric disturbances was diagnosed as $\mathrm{AD}$ by Alois Alzheimer in 1907, this disease was considered to be a relatively uncommon disorder with a variety of progressive and fatal neurological conditions including senile dementia and the early age at onset. Subsequent clinical and neuropathological studies identified senile plaques and NFTs as the most common causes of the disease in the elderly. $A \beta$ is produced by sequential proteolytic processing of a larger $\mathrm{A} \beta$ protein precursor (APP) by $\beta$-secretase to generate a large secreted fragment sA $\beta$ PP and a 99 aa cellular fragment CTF $\beta$ that includes $\mathrm{A} \beta$, the transmembrane domain and the intracellular domain of APP [3]. AD is usually recognized as a syndrome, a common clinical-pathological entity with multiple causes. Specifically, the diagnosis of this disease is based not only on memory loss and impairment of at least one other cognitive domain, but also on a decline in global function, a deterioration in the ability to perform activities of daily living, and the appearance of disturbance in social or occupational function. What's more, characteristic idiopathic psychometric deficits upon clinical evaluation and further postmortem confirmations of the presence of the characteristic lesions mentioned above are quite necessary for its diagnosis.

Considerable variability in initial clinical presentation may be dependent on the brain regions affected. Over time, $\mathrm{AD}$ could be divided into two clinical phases depending on 
the age of onset. A type of "presenile" dementia was usually defined for individuals younger than 65 years of age, whereas a similar dementia in the elderly, for example, in individuals over 65-year-old, was referred to as senile dementia of the Alzheimer type after the pioneering studies conducted by Roth et al. [4-6]. AD is now generally recognized as a single major cause of dementia with a prevalence that increases sharply after age 65 . It has been reported that rare early-onset forms of $\mathrm{AD}$ are linked directly to highly penetrant autosomal dominant mutations in one of three different genes: amyloid precursor protein (APP) gene, presenilin (PS) 1 gene, or presenilin 2 gene. Early-onset forms of $\mathrm{AD}$ generally have extensive lesions including a tendency for white matter lesions and "cotton wool" plaques in some early onset cases associated with exon 9 presenilin-1 mutations [7]. Interestingly, in addition to classic AD pathology, Lewy body pathology has also been described in familial early onset cases [8]. However, late-onset AD (LOAD) which accounts for approximately 95\% of all $\mathrm{AD}$ cases [9] likely results from the complex interplay of molecular, environmental, and genetic factors. It represents a significant and growing public health burden and is the third most costly medical conditions in the USA The causes of late-onset $\mathrm{AD}$ are not yet clarified, but aside from age, several other risk factors include family history of dementia, down syndrome, head trauma, being female, low education level, vascular disease, and environmental factors and genetic risk factors have been identified, therefore, high education, ingestion of estrogen, nonsteroidal anti-inflammatory drugs, and vitamin $\mathrm{E}$ may be protective for $\mathrm{AD}$. AD pathology is found prematurely in down syndrome, which argues in favor of the amyloid cascade hypothesis, given that the $\beta$-amyloid protein precursor $(\mathrm{A} \beta \mathrm{PP})$ can be found on chromosome 21 and that down syndrome subjects have an extra copy of chromosome 21. Similar pathological presentations have been found in cases of down syndrome and most of these pathological features may also be present to a lesser extent in a large proportion of aged nondemented controls, lending support to the possibility that such individuals are in an extremely early preclinical stage of AD [10]. Previous studies have demonstrated that the most potent cause of late-onset $\mathrm{AD}$ is the $\varepsilon 4$ allele of the apolipoprotein (apo) $\mathrm{E}$ gene (APOE) on chromosome 19 [11]. The effect appears to be dose dependent. It has been reported that the presence of a single $\varepsilon 4$ allele increases the risk of $\mathrm{AD}$ by 2 - to 4 -fold while the double $\varepsilon 4$ allele increases the risk of $\mathrm{AD}$ by 4 - to 8 -fold. However, possessing the $\varepsilon 4$ allele is neither necessary nor sufficient for the development of AD. Therefore, though APOE genotyping may be useful for confirmation in some patients with dementia when a diagnosis of $\mathrm{AD}$ is unclear, it is not recommended by experts as a predictive test for $\mathrm{AD}$ in asymptomatic individuals, whereas APOE genotyping could be used in patients with a clinical diagnosis of $\mathrm{AD}$ and it may increase the specificity of the diagnosis.

\section{Epidemiology}

$\mathrm{AD}$ constitutes approximately $65 \%$ to $75 \%$ of all dementia cases. The prevalence of dementia in the United States in individuals aged 65 years or older is about $8 \%$, incidence of $\mathrm{AD}$ increases with age, doubling every five to ten years from $1 \%$ to $2 \%$ at ages 65 to 70 years, to $30 \%$ and higher after the age of 85 years if those with milder forms of dementia or cognitive impairment are included. Rates of dementia are very much age dependent and increases exponentially with age. For persons between ages 65-69, 70-74, 75-79, 80-84, and 85 and older the incidence of $\mathrm{AD}$ has been estimated at $0.6 \%, 1.0 \%, 2.0 \%, 3.3 \%$, and $8.4 \%$ [12]. Prevalence increases from $3 \%$ among individuals aged $65-74$ to almost $50 \%$ among those 85 or older [13]. AD affects 25 million people worldwide and in the USA, prevalence was estimated at 5 million in 2007 and, by 2050, is projected to increase to 13 million [13]. Globally, the number of the elderly (aged 65 years and older) is projected to increase dramatically, more than doubling from 420 million in 2000 to 973 million in 2030 [1].

\section{Pathophysiology}

The exact mechanism of $\mathrm{AD}$ is still not clear. The most common and distinctive hallmark lesions present within the $\mathrm{AD}$ brains are the $\beta$-amyloid ( $\mathrm{A} \beta$-) containing senile plaques and the NFTs composed of hyperphosphorylated tau protein, which generate strong responses from the surrounding cellular environment and are responsible for much of the late-stage cognitive decline observed in $\mathrm{AD}$ patients. The neuritic plaque has been often highlighted as one of the major consensus criteria for the diagnosis of AD at autopsy. The other major hallmark NFTs are also occasionally called pretangles. Some studies have showed that the development of NFTs may protect against neuronal damage, since mutations in the $\mathrm{A} \beta$ precursor protein (APP) and the presence of NFT-containing neurons are associated with the reduced steady-state production of $A \beta$ and reduced levels of oxidative stress. Alternative theories for the pathogenesis of AD suggest that such pathological formations of senile plaques and NFTs are primarily responsible for neurodegeneration. For example, when $\mathrm{A} \beta$ has aggregated sufficiently, this protein elicits a neuroinflammatory response via the activation of microglia and astrocytes $[14,15]$. Following the initial neuroinflammatory response, the neurotoxic byproducts of inflammation cause additional oxidative damage to cells [16]. Similarly, the hyperphosphorylated tau fibrils create cytoskeletal stresses and promote neuronal dysfunction [17].

Neuronal and dendritic loss, neuropil threads, dystrophic neurites, granulovacuolar degeneration, Hirano bodies, and cerebrovascular amyloid are also typical of the AD brain. It is well recognized in recent years that [18] synapse loss is the most specific pathological feature of Alzheimer's disease, which is due at least in part to the recent studies to associate synapse loss with low-n soluble $\mathrm{A} \beta$ species. However, it should be pointed out that assessment of the synapse is not recommended in the diagnosis of $\mathrm{AD}$ at autopsy either by immunohistochemistry or electron microscopy [19].

The distinctive pathology between $\mathrm{AD}$ and aging is problematic, particularly in the elderly. Regarding the correlation between clinical diagnosis and pathological findings, it has 
been reported that $76 \%$ of brains of cognitively intact elderly patients were interpreted as $\mathrm{AD}$ brains [20].

\section{Oxidative Stress and Alzheimer's Disease}

Accumulating evidence suggests that brain tissues in $\mathrm{AD}$ patients are exposed to oxidative stress during the development of the disease. Oxidative stress or damage such as protein oxidation, lipid oxidation, DNA oxidation, and glycoxidation [21] is closely associated with the development of Alzheimer's disease. AD is characterized by neuronal and synaptic loss, formation, and accumulation of extracellular $\mathrm{A} \beta$ plaques produced from APP processing and intracellular NFTs composed of aggregated hyperphosphorylated tau proteins in brain, proliferation of astrocytes, and activation of microglial. Oxidative stress is generally characterized by an imbalance in production of reactive oxygen species (ROS) and antioxidative defense system which are responsible for the removal of ROS [22], both systems are considered to have major roles in the process of age-related neurodegeneration and cognitive decline. Reactive oxygen species (ROS) and reactive nitrogen species (RNS), including superoxide anion radical $\left(\mathrm{O}_{2}{ }^{--}\right)$, hydrogen peroxide $\left(\mathrm{H}_{2} \mathrm{O}_{2}\right)$, hydroxyl radical $(\bullet \mathrm{OH})$, singlet oxygen $\left({ }^{1} \mathrm{O}_{2}\right)$, alkoxyl radicals $(\mathrm{RO} \bullet)$, peroxyl radicals (ROO•), and peroxynitrites $\left(\mathrm{ONOO}^{-}\right)$, contribute to pathogenesis of numerous human degenerative diseases [23]. Certain antioxidants including glutathione, $\alpha$-tocopherol (vitamin E), carotenoids, ascorbic acid, antioxidant enzymes such as catalase and glutathione peroxidases are able to detoxify $\mathrm{H}_{2} \mathrm{O}_{2}$ by converting it to $\mathrm{O}_{2}$ and $\mathrm{H}_{2} \mathrm{O}$ under physiological conditions [24]. However, when ROS levels exceed the removal capacity of antioxidant system under pathological conditions or by aging or metabolic demand, oxidative stress occurs and causes biological dysfunction [24]. For example, high levels of protein oxidation, lipid oxidation, advanced DNA oxidation and glycoxidation end products, carbohydrates, formation of toxic substances such as peroxides, alcohols, aldehydes, free carbonyls, ketones, cholestenone, and oxidative modifications in nuclear and mitochondrial DNA [25] are the main manifestations of oxidative stress or damage occurred during the course of Alzheimer's disease. Elevated levels of those oxidated formations mentioned above have been described not only in brain, but in cerebrospinal fluid (CSF), blood, and urine of $\mathrm{AD}$ patients $[25,26]$.

Age-related memory impairments correlate with a decrease in brain and plasma antioxidants defense mechanism. An important aspect of the antioxidant defense system is glutathione (GSH) which is responsible for the endogenous redox potential in cells [27]. Its most important function is to donate electrons to ROS so as to scavenge them. Intracellular glutathione concentration decreases with age mammalian brain regions including hippocampus $[28,29]$ which may lead to a situation that the rate of ROS production exceeds that of removal thus induces oxidative stress. Therefore, the imbalance among the radical detoxifying enzymes is a cause for oxidative stress in AD.
Many studies have provided evidence for the deleterious consequences of oxidative stress products on certain cellular targets in AD. Protein oxidation and the oxidation of nuclear and mitochondrial DNA have been observed in both $\mathrm{AD}$ patients and in elderly patients without $\mathrm{AD}$, but the oxidation of nuclear and mitochondrial DNA appears to be present in the parietal cortex [30], whereas protein oxidation appears to be more marked in $\mathrm{AD}$ patients in the regions presenting the most severe histopathologic alterations [31]. In addition, increased lipid peroxidation in the temporal lobe where histopathologic alterations are very noticeable in the $\mathrm{AD}$ brains has been observed. The APOE genotype and those with the $\varepsilon 4$ allele seem to be more susceptible to peroxidation than those without this allele [32].

As mentioned earlier, several studies have identified many end products of peroxidation including malondialdehyde [33], peroxynitrite [14, 34], carbonyls [35], advanced glycosylation end products (AGEs) [33], superoxide dismutase-1 [36], and heme oxygenase-1 [37] which is a cellular enzyme that is upregulated in the brain and in other tissues in response to an oxidative stimuli in the brains of $\mathrm{AD}$ patients, particularly in the NFTs.

\section{Lipid Oxidation in AD}

The lipoperoxidation phenomena also exert important influences on the pathogenesis of $\mathrm{AD} . \mathrm{A} \beta$ causes lipoperoxidation of membranes and induces lipid peroxidation products. Lipids are modified by ROS and the correlations among lipid peroxides, antioxidant enzymes, senile plaques, and NFTs in AD brains are very strong. Markesbery showed that lipid peroxidation is a major cause of depletion of membrane phospholipids in AD [38]. Several breakdown products of oxidative stress have been observed in $\mathrm{AD}$ brains compared to age-matched controls [39], including acrolein, malondialdehyde, F2-isoprostanes, and 4-hydroxy2,3-nonenal (HNE) which is the most highly reactive and the major neuronal and hippocampal cytotoxic lipid peroxidation product in high concentrations in $\mathrm{AD}$ patients and it contributes to impairments of the function of membrane proteins such as the neuronal glucose transporter GLUT 3, inhibition of neuronal glucose and glutamate transporters, inhibition of $\mathrm{Na}^{+} / \mathrm{K}^{+}$ATPases, activation of kinases, and dysregulation of ionic transfers and calcium homeostasis, thus the increased calcium concentration could itself cause a cascade of intracellular events, resulting in increased ROS and cellular death that ultimately induce an apoptotic cascade mechanism, and lead to neurodegeneration in $\mathrm{AD}$. Some other supporting evidence shows that the glutamatedependent flux of calcium is associated with the production of free radicals by the mitochondria. It is also worth mentioning that elevated level of cerebrospinal fluid concentrations of F2-isoprostane which is produced by free radical-catalyzed peroxidation of arachidonic acid has been observed in $\mathrm{AD}$ patients [40]. This discovery is significant not only because it confirms that lipid peroxidation is elevated in $\mathrm{AD}$, but because it provides indications of the possible use of the quantification of cerebrospinal fluid F2-isoprostane 
concentrations as a biomarker for AD diagnosis. In addition, Busciglio and Yankner showed that in down syndrome, which involves a similar neurodegenerative component to that of $\mathrm{AD}$, neuronal death occurs according to a process of apoptosis that is related to an increase in lipoperoxidation and can be stopped by catalase and free radical scavengers [41].

\section{DNA Oxidation in AD}

DNA bases are vulnerable to oxidative stress damage and it has been observed in $\mathrm{AD}$ brains that ROS induces calcium influx via glutamate receptors and triggers excitotoxic responses leading to cell death. DNA and RNA oxidation is marked by increased levels of 8-hydroxy-2-deoxyguanosine (8OHdG) and 8-hydroxyguanosine (8OHD) [42] which mostly localized in A $\beta$ plaques and NFTs. Increased levels of DNA strand breaks found in AD brains were first considered to be parts of apoptosis, but it is increasingly recognized that oxidative damage is responsible for DNA strand breaks, and this is consistent with the increased free carbonyls in the nuclei of neurons and glia in $\mathrm{AD}$.

\section{Glycoxidation in AD}

Advanced glycation end products (AGEs), a diverse class of posttranslational modifications, are formed by a nonenzymatic reaction of a sugar ketone or aldehyde group with longlived protein deposits and are also potent neurotoxins and proinflammatory molecules. Glycation of proteins starts as a nonenzymatic process with the spontaneous condensation of ketone or aldehyde groups of sugars with the free amino groups of a protein or aminoacid specifically lysine, arginine, and possibly histidine [43]. Accumulation of AGEs in the brain is a feature of aging and is also implicated in the pathophysiological development of $\mathrm{AD}$. There is increasing evidence that the insolubility of $\mathrm{A} \beta$ plaques is caused by extensive covalent protein cross-linking and AGEs can be cross-linked to long-lived proteins [44]. Extracellular AGEs accumulation is caused by an accelerated oxidation of glycated proteins, also called glycoxidation and has been demonstrated in senile plaques in different cortical areas in both primitive and classic plaques. Immunohistochemical studies demonstrate that AGEs colocalize to a very high degree with APOE [45]. Some studies have shown the presence of AGEs in association with two major proteins of $\mathrm{AD}, \mathrm{A} \beta$ and the microtubule-associated protein tau [33] which is the major component of the NFTs, and it has been shown to be subject to intracellular AGEs formation. Tau protein isolated from brains of $\mathrm{AD}$ patients can be glycated in the tubulin-binding region, giving rise to the formation of $\beta$-sheet fibrils [46], leading to its disability to bind to microtubules. Taken together, it can be concluded that AGEs are involved in the pathogenesis of $\mathrm{AD}$, and free radicals are also involved in glycation processes and can promote the formation of $\mathrm{A} \beta$ cross-linking. Additionally, it has been reported that AGEs and $\beta$-amyloid activate specific receptors such as the receptor for advanced glycation end products (RAGE) and the class A scavenger-receptor to foster ROS production and regulate gene transcriptions of various factors participated in inflammation through $\mathrm{NF} \kappa \mathrm{B}$ activation [47].

\section{Mitochondrial Dysfunction in Alzheimer's Disease}

Mitochondria has been shown to be the center of ROS production. In $\mathrm{AD}$, alterations in mitochondrial function and damaged mitochondria in the course of aging and neurodegeneration have been observed [48]. Consistent defects in mitochondria in $\mathrm{AD}$ include defects of the electron transport chain which are major factors contributing to the production of free radicals and the deficiencies in several key enzymes responsible for oxidative metabolism including $\alpha$-ketoglutarate dehydrogenase complex (KGDHC) and pyruvate dehydrogenase complex (PDHC), which are two important enzymes involved in the rate-limiting step of tricarboxylic acid cycle and cytochrome oxidase (COX) which is the terminal enzyme in the mitochondrial respiratory chain that is responsible for reducing molecular oxygen [49]. It has been reported that postmortem cytochrome-c oxidase activity was lower than normal in the cerebral cortex (frontal, parietal, temporal, and occipital) [50], in the dentate gyrus and the CA4, CA3, and CA1 zones of the hippocampus and in the platelets of $\mathrm{AD}$ brains. A decline in cytochromec oxidase activity rather than amounts of cytochrome-c oxidase is associated with decreased expression of messenger RNA (mRNA) molecules, which is lower in the midtemporal region of the brains of $\mathrm{AD}$ patients [51]. The functional abnormalities in mitochondria promote the production of ROS. In addition, it has been found that damaged mitochondrial DNA (mtDNA) presents in vulnerable neurons in $\mathrm{AD}$ brains [52], and formation of mitochondrial-derived lysosomes and lipofuscin is evident in almost all of $\mathrm{AD}$ neurons [53]. Quantitative morphometric measurements of the percentage of different types of mitochondria (normal, partially damaged, and completely damaged) indicate that neurons in $\mathrm{AD}$ brains show an obvious lower percentage of normal mitochondria and a significantly higher percentage of the completely damaged mitochondria compared to the aged-matched control group [54]. The cybrid technique is very promising for the study of neurodegenerative diseases [54]. Some studies from cybrid cell lines with mitochondria DNA from AD patients showed abnormal mitochondrial morphology, membrane potential, and ROS production, which demonstrated that mutant mitochondrial DNA in $\mathrm{AD}$ contributed to its pathology. Low vascular blood flow, $\mathrm{A} \beta$ and $\beta$-amyloid protein precursor $(\mathrm{A} \beta \mathrm{PP})$ processing machinery have also been implicated in the development of $\mathrm{AD}$ and are associated with dysfunctional consequences for mitochondrial homeostasis [55]. $\mathrm{A} \beta \mathrm{PP}$ is present in the mitochondrial import channel and potentially inhibits mitochondrial import [56], and it also impairs mitochondrial energy metabolism thus causes mitochondrial abnormalities. Furthermore, homocysteine is also a strong risk factor in the course of $\mathrm{AD}$ development and it inhibits several genes 
encoding mitochondrial proteins and favors ROS production [57]. Apolipoprotein E4 (APOE4) is another factor that leads to mitochondrial dysfunction. Previous studies have shown that more APOE4 fragment in AD brains than in the age-matched controls, and it shows toxicity and impairs mitochondrial function and integrity [58].

The reason why mitochondrial defects exert an influence on the development of AD is that they can trigger two harmful events: the production of destructive free radicals and a reduction in energy resources. A reduction in the regional cerebral metabolic glucose concentration was observed in $\mathrm{AD}$ patients using positron emission tomography at rest. This was seen throughout the neocortex and was found to associate with the severity of dementia.

\section{Therapeutic Strategies for Alzheimer's Disease}

While no drug has been shown to completely protect neurons, there are two possible conceptual approaches to the treatment of $\mathrm{AD}$. One approach is the treatment that prevents the onset of the disease by sequestering the primary progenitors or targets and reduces the secondary pathologies of the disease, slows disease progression or delay onset of disease, leads to the cessation or even the repair of neuronal damage after onset of disease, and eventually prevents the development of $\mathrm{AD}$; another approach is the symptomatic treatment that treats the tertiary cognitive symptoms of the disease and protects from further cognitive decline. This approach reflects the current state of treatment and usually includes treating the cognitive impairment, decline in global function, deterioration in the ability to perform activities of daily living and behavioral disturbances. Notably, the appropriate treatment strategies depend on the severity of the disease and the specificity of each individual; however, currently available therapeutic agents are mainly targeted at specific symptoms of $\mathrm{AD}$, agents such as cholinesterase/acetylcholinesterase inhibitors which are involved in the enhancement of cholinergic neurotransmission and inhibit the degradation of acetylcholine within the synapse are the major treatments for Alzheimer's disease. Other therapeutic agents and strategies including neurotrophins, antioxidants, statins, nonsteroidal anti-inflammatory drugs (NSAIDs), hormone replacement therapy, blocking of excitotoxicity, the $\mathrm{A} \beta$ vaccine trials, immunotherapy, and secretase effectors have also been studied, but their use remains controversial. Therefore, preventive and disease-modifying treatment strategies still need further investigations for the eradication of $\mathrm{AD}$ from the general population.

Our knowledge of the pathophysiology and the history of $\mathrm{AD}$ has been increased greatly over the past decade, yet the definitive causes remain unclear and the cures have been elusive. Antioxidant therapy, as one of the promising therapeutic strategies for AD, has been studied for years. It has been reported that antioxidants such as lipoic acid (also called thioctic acid), vitamin $\mathrm{E}$, vitamin $\mathrm{C}$ and $\beta$-carotene may help break down intracellular and extracellular superoxide radicals and $\mathrm{H}_{2} \mathrm{O}_{2}$-cell-damaging compounds that are byproducts of normally functioning cells before these radicals damage cells or activate microglia through their action as intracellular second messengers $[59,60]$. However, antioxidants may act as prooxidants under some defined circumstances. For example, vitamin E acts as a prooxidant in isolated lipoprotein suspensions such as parenteral nutrition solutions in clinical conditions [61]. The prooxidative activity of vitamin $\mathrm{E}$ at low concentrations of various oxidants has been widely documented in plasma lipoproteins [6264]. Multiple lines of evidence suggest that the activity of vitamin E towards oxidation of plasma lipoproteins depends on oxidative conditions. Vitamin E consistently inhibits oxidation under strong oxidative conditions which is at high fluxes of free radicals as compared to the concentration of the vitamin [63], while under mild oxidative conditions, vitamin $\mathrm{E}$ behaves as a prooxidant and accelerates oxidation by a mechanism of tocopherol-mediated peroxidation [63]. In addition, in 2004, Kontush and Schekatolina reported that computer modeling of the influence of vitamin $\mathrm{E}$ on lipoprotein oxidation showed that the vitamin E developed antioxidative activity in CSF lipoproteins in the presence of physiologically relevant, low amounts of oxidants [65]. By contrast, under similar conditions, vitamin $\mathrm{E}$ behaved as a prooxidant in plasma lipoproteins, consistent with the model of tocopherol-mediated peroxidation established by Stocker in 1994 [62]. Vitamin A [66] and trace elements with antioxidant properties such as copper and selenium [67] may also become prooxidant both in vivo and in vitro under the right conditions. The prooxidant effects of selenium have been investigated in cultured vascular cells exposed to parenteral nutrition containing various forms and quantities of selenium [67]. In a recent study, Nakamura et al. [68] suggested that vitamin $C$ may play an important role to prevent the prooxidant effect of vitamin $\mathrm{E}$ in $\mathrm{LDL}$ oxidation. Vitamin C combined with ferrous iron is a standard free radical generating system. The theory that the entire antioxidant systems normally form an important and complex network suggests that antioxidant intake from food is superior to vitamin supplements because highdose supplementation with a single antioxidant vitamin in isolation could disrupt the balance of the network [69].

Therefore, taking considerations of the pathogenesis and oxidative damage-related mechanisms underlying $\mathrm{AD}$, the network existing among the different antioxidants, and the relationship between prooxidant and antioxidant factors, this paper mainly focuses on the recent developments of common used antioxidants therapies for Alzheimer's disease and thus provides indications for future potential antioxidants therapeutic methods of neurodegenerative diseases. The chemical structure and potential function of the antioxidants are summarized in Table 1.

\section{Antioxidant Therapies}

10.1. Vitamins and Carotene. Vitamin E ( $\alpha$-tocopherol), vitamin $C$, and $\beta$-carotene are exogenous chain-breaking 
TABLE 1: Chemical structure and potential function of the antioxidants.

Antioxidant Chemical structures

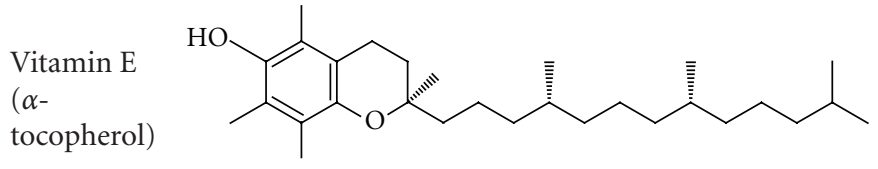

Potential functions

A powerful, lipid-soluble chain-breaking antioxidant found in lipid membranes, circulating lipoproteins and low-density lipoprotein (LDL) particles [70] and has been shown to decrease Free-radical-mediated damage caused by toxic chain reactions in neuronal cells and helps to inhibit dementia pathogenesis in mammalian cells.

A water-soluble antioxidant, and an inhibitor of lipid peroxidation, acts as a major defense against free radicals in whole blood and plasma.

$\beta$-carotene

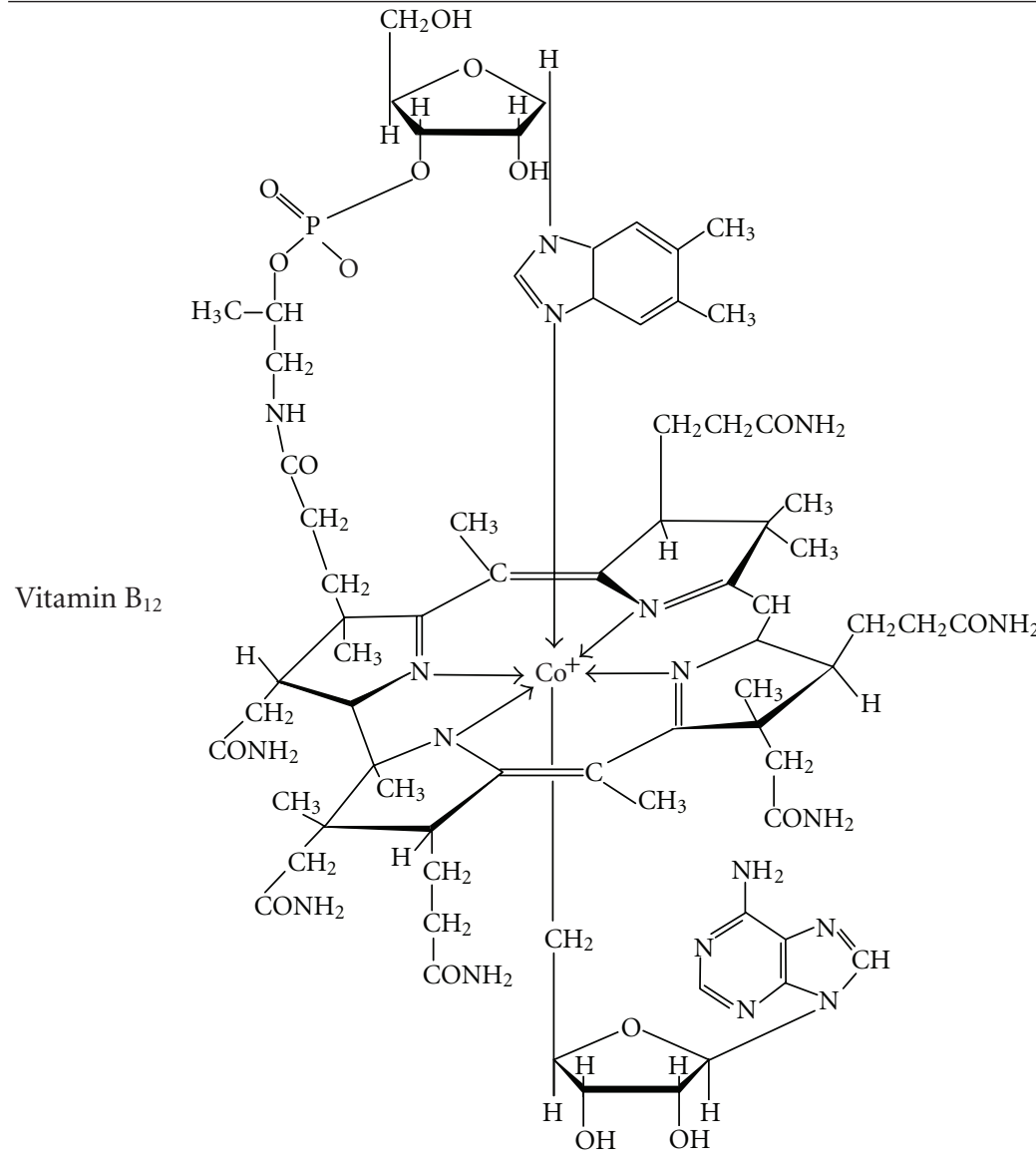

An antioxidant that increases choline acetyltransferase activity in cholinergic neurons in cats [88] and improves cognitive functions in $\mathrm{AD}$ patients.
LA $(\alpha$-lipoic acid)<smiles>O=C(O)CCCC[C@@H]1CCSS1</smiles>

A coenzyme of mitochondrial pyruvate dehydrogenase and $\alpha$-ketoglutarate dehydrogenase, can recycle other antioxidants such as vitamin $\mathrm{C}$ and $\mathrm{E}$ and glutathione and increase the production of acetylcholine or as a chelator of redox-active metals to combat the accumulation of lipid peroxidation products [94]. 
Table 1: Continued.

Antioxidant Chemical structures<smiles>CCC(C)=CCCC1=C(C)C(=O)C(OC)=C(OC)C1=O</smiles>

Selenium
Potential functions

A cofactor of the electron transport chain and it preserves mitochondrial membrane potential during oxidative stress and protects neuronal cells through attenuating $\mathrm{A} \beta$ overproduction and intracellular $\mathrm{A} \beta$ plaque deposits.
Szeto Schiller

(SS) peptide

31
A cofactor of glutathione peroxidase, and Se-glutathione peroxidase can also act as an antioxidant.

\section{MitoQ}

An antioxidant targeted to mitochondria and is produced by conjugation of the lipophilic triphenylphosphonium $\left(\mathrm{TPP}^{+}\right)$cation to coenzyme Q [100].

A mitochondria-targeted antioxidants (MTAs) concentrate in the inner mitochondrial membrane and decrease mitochondrial toxicity [103], they can prevent the neurotoxin 1-methyl-4-phenylpyridium $\left(\mathrm{MPP}^{+}-\right)$induced inhibition of oxygen consumption and ATP production and mitochondrial swelling [106].

Caffeine<smiles>COc1cc(/C=C/C(=O)/C=C(O)/C=C/c2ccc(O)c(OC)c2)ccc1O</smiles>

An antioxidant that has antioxidant, antiinflammatory, and antiamyloid pathology activity in an Alzheimer transgenic mouse models,

Curcumin<smiles>CCCCCCCC(=O)CC(=O)C=Cc1ccc(O)c(OC)c1</smiles>
and it inhibits enzymes lipoxygenase and cyclooxygenase 2 that are responsible for the synthesis of the proinflammatory leukotrienes, prostaglandins, and thromboxanes [108].
Berberine<smiles>COc1ccc2cc3[n+](cc2c1OC)CCc1cc2c(cc1-3)OCO2</smiles>

an antioxidant that exhibits anti-AD effects through both ChEs and $\mathrm{A} \beta$ pathways, and can also inhibit ROS and RNS [23]. 
TABle 1: Continued.

An antioxidant that exhibits anti-AD effects through
both ChEs and $\mathrm{A} \beta$ pathways and can also inhibit
ROS and RNS [23].

A flavonoid derived from the herb milk thistle
(Silybum marianum), it prevents memory
impairment and oxidative damage induced by $\mathrm{A} \beta$ in
mice.

Ginkgo

biloba

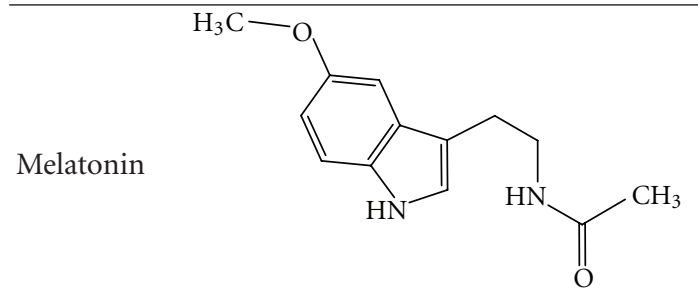

Selegiline
(L-deprenyl)



A natural plant that contains a variety of compounds such as flavonoids and terpenoids which have free radical scavenging ability, and it can reduce amyloid precursor protein [112] and inhibit $\mathrm{A} \beta$ aggregation in vitro.

A mammalian hormone synthesized mainly in the pineal gland, and it scavenges oxygen and nitrogen-based reactants generated in mitochondria by stimulating the expression and activity of glutathione peroxidase, superoxide dismutase, and NO synthetase [116], and it also contributes to the reduction of oxidative damage in cells [79].

A selective monoamine oxidase-B inhibitor which can generate potent vasodilator nitric oxide particularly in cerebral blood vessels rapidly [127] and protect the vascular endothelium from the toxic effects of $\mathrm{A} \beta$ peptide and enhance the function of nigral neurons or enhance their survival by inhibiting oxidative deamination $[73,115]$.

An antioxidant which protects neurons from the toxicity of $\mathrm{A} \beta$. 
TABle 1: Continued.

Antioxidant Chemical structures

antioxidants, which decrease free-radical-mediated damage caused by toxic chain reactions in neuronal cells and help to inhibit dementia pathogenesis in mammalian cells. The most important lipid-phase antioxidant is $\alpha$-tocopherol which is a powerful, lipid-soluble chain-breaking antioxidant found in lipid membranes, circulating lipoproteins and low-density lipoprotein (LDL) particles [70]. In experimental studies, vitamin $\mathrm{E}$ has been shown to attenuate toxic effects of $\beta$-amyloid and improve cognitive performance in rodents [71, 72]. In 1997, Sano et al. reported that in patients with moderately severe impairment from $\mathrm{AD}$, treatment with $\alpha$ tocopherol (2000 IU a day) reduces neuronal damage and slows the progression of $\mathrm{AD}$ [73], which indicates that the use of $\alpha$-tocopherol may delay clinically important functional deterioration in AD patients. In 2004, Sung et al. reported that vitamin $\mathrm{E}$ suppresses brain lipid peroxidation and significantly reduces $\mathrm{A} \beta$ levels and senile plaque deposition in Tg2576 mice when it was administered early prior to the appearance of the pathology during the evolution of $\mathrm{AD}$. However, if vitamin E supplementation was started at a later time point when amyloid plaques were already deposited, no significant effect is observed on the amyloidotic phenotype of these animals despite a reduction in brain oxidative stress [74]. In 2004, Nakashima et al. showed that treatment with $\alpha$-tocopherol in transgenic ( $\mathrm{Tg}$ ) mice overexpressing human tau protein decreased carbonyls and 8-OHdG [75]. In 2007, Dias-Santagataet reported that administration of $\alpha$ tocopherol significantly suppressed tau-induced neurotoxicity in Drosophila [76], and similar beneficial results were recently reported by others using transgenic mouse models of human tauopathies and $\mathrm{AD}$ [75], which underscored the therapeutic potential of vitamin E. In 2009, Pavlik et al. reported that patients whose regimens included vitamin $\mathrm{E}$ tended to survive longer than those taking no drug or a ChEI alone, and there was no evidence that treatment with high doses of vitamin $\mathrm{E}$ had an adverse effect on survival in an $\mathrm{AD}$ cohort followed-up for up to 15 years [77].

Vitamin C is a water-soluble antioxidant which is also a powerful inhibitor of lipid peroxidation and acts as a major defense against free radicals in whole blood and plasma. Bagi et al. have shown that chronic vitamin C treatment is able to decrease high levels of isoprostanes and oxidative stress in vivo, enhance NO bioavailability, restore the regulation of shear stress in arterioles, and normalize systemic blood pressure in methionine dietinduced hyperhomocysteinemia rats [78]. Besides, vitamin
$\mathrm{C}$ reduces $\alpha$-tocopheroxyl radicals rapidly in membranes and LDL to regenerate $\alpha$-tocopherol and possibly inhibits $\alpha$ tocopheroxyl radical-mediated propagation [79]. Carotenoid is another lipid-soluble antioxidant which may reduce lipid peroxidation and improve antioxidant status [80]. The most known and studied carotenoid is the $\beta$-carotene which is a potent antioxidant able to quench singlet oxygen rapidly [81]. Vitamin C, vitamin E, and carotenoids have shown to synergistically interact against lipid peroxidation $[79,82]$. However, it is not completely defined whether nutrient therapy is an effective treatment of Alzheimer disease. Lloret et al.'s findings indicate that vitamin $\mathrm{E}$ does not lower plasma oxidative stress for half of the $\mathrm{AD}$ patients [83] and some other study results have suggested that either through the diet or by supplements, consuming carotenes or vitamins $\mathrm{C}$ and $\mathrm{E}$ did not decrease the risk of developing $\mathrm{AD}$, which indicates that antioxidant therapies have only enjoyed general success in preclinical studies in animal models but little benefit in human preventive studies or clinical trials [84]. In 2002, Morris et al. reported that higher intake of foods rich in vitamin $\mathrm{E}$ may modestly reduce long-term risk of dementia and $\mathrm{AD}$ after adjustment for age, education, sex, race, $\mathrm{APOE} \varepsilon 4$, and length of followup, and this association was observed only among individuals without the APOE 4 allele [85], while dietary intakes of vitamin $C, \beta$-carotene, and flavonoids were not associated with dementia risk. Thus, future trials are still needed with a special consideration and focus on individual monitoring of therapeutic potential to avoid toxicity and assess biomarkers of efficacy [86].

In addition to vitamin $E$ and vitamin $C$, vitamin $B_{12}$ may also have some roles in the treatment of $\mathrm{AD}$. In most studies the serum levels of vitamin $B_{12}$ in $A D$ patients were significantly lower than that of control group, which may partly contribute to degeneration of neurons [87]. Several studies indicated that vitamin $\mathrm{B}_{12}$ supplementation increased choline acetyltransferase activity in cholinergic neurons in cats [88] and improved cognitive functions in $\mathrm{AD}$ patients [89]. Therefore, the inclusion of vitamin $B_{12}$ in multiple antioxidant therapeutic strategies may be useful.

\section{Antioxidant Enzymes}

Preventive antioxidants such as metal chelators, glutathione peroxidases, and SOD enzymes including a cytoplasmic antioxidant enzyme-copper-zinc superoxide dismutase 
(CuZnSOD) [90] and a prosurvival mitochondrial antioxidant enzyme-MnSOD, repair enzymes such as lipases, proteases, and DNA repair enzymes [21] have also been shown to be essential for neural survival and neuronal protection against oxidative damages [91] and can be used to treat cognitive and behavioral symptoms of Alzheimer's disease [21]. Recent studies suggest that MnSOD plays a protective role during $\mathrm{AD}$ development, and MnSOD deficiency increases $A \beta$ levels and accelerates the onset of behavioral alteration in APP transgenic mice [92].

\section{Mitochondria-Targeted Antioxidants (MTAs)}

Besides well-characterized antioxidants such as vitamin A, carotenoids, vitamin $\mathrm{C}$, and vitamin $\mathrm{E}$ mentioned above, other antioxidants such as $\alpha$-lipoic acid (LA), coenzyme Q10, NADH, Mito Q, Szeto Schiller (SS) peptide, and glutathione which is effective in catabolizing $\mathrm{H}_{2} \mathrm{O}_{2}$ and anions have some potential therapeutic value in the treatment of certain neurodegenerative diseases. Mitochondrial dysfunction is involved in the pathogenesis of many neurodegenerative diseases including Alzheimer's disease, so developing new therapeutic strategies targeting mitochondrial may shed a new light to $\mathrm{AD}$ treatment. It is known that oxidative stress induces mitochondrial fragmentation and altered mitochondrial distribution in vitro, and it also causes both structurally and functionally damage of mitochondria during pathogenesis of Alzheimer's disease [93]. Since overproduction of ROS by mitochondria is one of the major factors that contribute to the course of $\mathrm{AD}$, many drugs targeting mitochondria tested or in development belong to metabolic antioxidants. Those antioxidants including R- $\alpha$-lipoic acid (LA) and coenzyme Q10 (CoQ10) that can easily penetrate not only the cell, but the mitochondria, may provide the greatest protection.

LA ( $\alpha$-lipoic acid), also called thioctic acid, as a powerful antioxidant therapeutic and the coenzyme of mitochondrial pyruvate dehydrogenase and $\alpha$-ketoglutarate dehydrogenase, can recycle other antioxidants such as vitamins $\mathrm{C}$ and $\mathrm{E}$ and glutathione and increase the production of acetylcholine or as a chelator of redox-active metals to combat the accumulation of lipid peroxidation products [94]. In this respect, LA used in conjunction with acetyl carnitine protects neuronal cells via cell signaling mechanisms including some extracellular kinase signaling pathways which are dysregulated in $\mathrm{AD}$ [95]. It has been reported that chronic administration of the antioxidant LA decreased the expression of lipid peroxidation markers of oxidative modification but not $\beta$ amyloid load within the brains of both control and $\mathrm{AD}$ mice models, and LA treatment improved Morris water maze performance in the $\mathrm{Tg} 2576$ mouse model but was ineffective at altering cognition in the Y-maze test or in the wild-type group for both tests [96]. Therefore, taken together results obtained from previous studies, we conclude the action of LA may be targeting mitochondria, the most affected organelle responsible for $\mathrm{AD}$ development.

CoQ10 (ubiquinone) is a potent antioxidant and also an important cofactor of the electron transport chain where it accepts electrons from complex I and II. It preserves mitochondrial membrane potential during oxidative stress and protects neuronal cells through attenuating $\mathrm{A} \beta$ overproduction and intracellular $\mathrm{A} \beta$ plaque deposits. It is well known that mitochondrial dysfunction is associated with $\mathrm{AD}$, and coenzyme Q10 and nicotinamide adenine dinucleotide (NADH) are needed for the generation of ATP by mitochondria, so it is essential to use these antioxidants for AD prevention. A study has shown that coenzyme Q10 (ubiquinol) scavenges peroxy radicals faster than $\alpha$-tocopherol [97] and, like vitamin $\mathrm{C}$, can regenerate vitamin $\mathrm{E}$ in a redox cycle [98]. However, it is weaker to improve clinical symptoms in patients with mitochondrial encephalomyopathies [98]. $\mathrm{NADH}$ administration $(10 \mathrm{mg} /$ day before meal) has been shown beneficial in a pilot study of $17 \mathrm{AD}$ patients [99]. What's more, it has been suggested that selenium is a cofactor of glutathione peroxidase, and Se-glutathione peroxidase can also act as an antioxidant. Therefore, Selenium supplementation together with other antioxidants may also contribute to therapeutic strategies of AD.

Mito $\mathrm{Q}$ is another promising therapeutic antioxidant that has been successfully targeted to mitochondria, and it is produced by conjugation of the lipophilic triphenylphosphonium $\left(\mathrm{TPP}^{+}\right)$cation to coenzyme Q [100]. With help of $\mathrm{TPP}^{+}$, coenzyme $\mathrm{Q}$ penetrates into the membrane core and reaches the mitochondrial matrix where it is reduced to its active form (the antioxidant ubiquinol) by complex II to decrease lipid peroxidation, resulting in reduced oxidative damage [101]. It has been reported that Mito Q also exerts protective effects on cells by reducing free radicals, decreasing oxidative damage, and maintaining mitochondrial functions [102]. Some studies report that Szeto Schiller (SS) peptide 31, another kind of mitochondria-targeted antioxidants (MTAs) concentrates in the inner mitochondrial membrane and decreases mitochondrial toxicity [103]. Intracellular concentrations of $[3 \mathrm{H}]$ SS-31 were 6-fold higher than extracellular concentrations [104]. In 2010, Manczak et al. reported that MitoQ and SS31 prevent A $\beta$ toxicity in mitochondria on neurons from a Tg2576 mouse model and on mouse neuroblastoma $(\mathrm{N} 2 \mathrm{a})$ cells incubated with the $\mathrm{A} \beta$ peptide, which suggested that MitoQ and SS31 are warranted to act as potential drugs to treat AD patients [105]. Studies with isolated mitochondria showed that both SS31 and SS20 prevented the neurotoxin 1-methyl-4-phenylpyridium $\left(\mathrm{MPP}^{+}-\right)$induced inhibition of oxygen consumption and ATP production and mitochondrial swelling [106]. These findings provide strong evidence that neuroprotective peptides such as SS-31 which target both mitochondrial dysfunction and oxidative damage are promising for the treatment of Alzheimer's disease [104].

\section{Dietary Supplements}

Various dietary supplements have been also shown to provide treatment of $\mathrm{AD}$ such as omega- 3 polyunsaturated fatty acid (docosahexaenoic acid) [21], caffeine, and curry spice curcumin. Caffeine (500 mg or 5-6 cups of coffee a day) [106], epigallocatechin-gallate esters from green tea [106] 
and red wine (Cabernet Sauvignon) have been shown to inhibit amyloidosis and $\mathrm{A} \beta$ production in both cell culture and animal models. Caffeine has antioxidant properties and has been demonstrated to reduce brain $\mathrm{A} \beta$ levels in transgenic mouse models for early-onset familial AD. In 2010, Prasanthi et al. reported that in the cholesterol-fed rabbit model system for late-onset sporadic $\mathrm{AD}$, caffeine decreases cholesterol-enriched diet-induced increase in $A \beta$ production and accumulation, reduces cholesterol-induced increase in phosphorylation of tau, attenuates cholesterolinduced increase in ROS and 8-Iso-PGF2 $\alpha$ levels, reduces glutathione depletion, and also protects against cholesterolinduced ER stress [107]. In addition, there is substantial in-vitro data indicating that curry spice curcumin is a promising agent in the treatment or prevention of $\mathrm{AD}$. It has antioxidant, antiinflammatory, and anti-amyloid pathology activity in an Alzheimer transgenic mouse models since it inhibits enzymes lipoxygenase and cyclooxygenase 2 that are responsible for the synthesis of the proinflammatory leukotrienes, prostaglandins, and thromboxanes [108]. It has also reported that curry spice curcumin reduces carbonyls and facilitates disaggregation of $\mathrm{A} \beta$ and reduction in $\mathrm{AD}$ associated neuropathology in APP Tg2576 mice [109]. Nonetheless, important information regarding curcumin bioavailability, safety, and tolerability, particularly in the elderly is lacking. Various other factors including lifestyle factors such as calorie restriction [110], high activity in environmental enrichment and voluntary exercise have been shown to synergistically interact with antioxidants in attenuating $\mathrm{AD}$ neuropathophysiology.

\section{Traditional Herbal Antioxidants}

Some traditional herbal antioxidants also exhibit potential for $\mathrm{AD}$ treatment. Jung et al. reported that three major alkaloids in Coptidis Rhizoma-groenlandicine, berberine, and palmatine can potentially exhibit anti-AD effects through both ChEs and $\mathrm{A} \beta$ pathways and antioxidant capacities to inhibit ROS and RNS [23]. In addition, silibinin (silybin), a flavonoid derived from the herb milk thistle (Silybum marianum), has been also shown to have antioxidative properties. Silibinin prevents memory impairment and oxidative damage induced by $\mathrm{A} \beta$ in mice and may be a potential therapeutic agent for Alzheimer's disease [111]. Ginkgo biloba is a natural plant that contains a variety of compounds such as flavonoids and terpenoids which have free radical scavenging ability. Previous studies have shown that Ginkgo biloba can reduce amyloid precursor protein and inhibit $\mathrm{A} \beta$ aggregation in vitro. However, Stackman et al. have reported that Tg2576 mice treated with Ginkgo biloba showed cognitive improvement without any effects on $A \beta$ levels or senile plaque [112]. In 2010, Garcia-Alloza et al. reported that there was no significant effect on senile plaque size after treatment with Ginkgo biloba, and it did not show any effects on $A \beta$ levels measured postmortem by ELISA [113]. In addition, there have been several reports of serious side effects associated with commercially available ginkgo, including coma, bleeding, and seizures [114]. At present, there is still little evidence to support the use of Ginkgo biloba for the treatment of $\mathrm{AD}$ [115].

\section{Other Antioxidants}

15.1. Melatonin. Melatonin is a mammalian hormone synthesized mainly in the pineal gland, and it scavenges oxygen and nitrogen-based reactants generated in mitochondria by stimulating the expression and activity of glutathione peroxidase, superoxide dismutase, and NO synthetase [116], and it also contributes to the reduction of oxidative damage in cells [79]. Currently conduced studies have shown that antioxidant melatonin could inhibit $\mathrm{A} \beta$-induced toxicity [117] and mitigate tau hyperphosphorylation [118-123]. In vivo, melatonin improved learning and memory deficits in an APP695 transgenic mouse model and in vitro, melatonin attenuated $\mathrm{A} \beta$-induced apoptosis in $\mathrm{AD}$ cell models such as mouse microglial BV2 cells, rat astroglioma C6 cells and PC12 cells [124]. Besides, studies in transgenic AD mice and cultured cells have suggested that administration of melatonin inhibited the $\mathrm{A} \beta$-induced mitochondria-related bax increase and it may also initiate the survival signal pathways. Another experiment demonstrated that melatonin inhibited the phosphorylation of NADPH oxidase via a $\mathrm{PI} 3 \mathrm{~K} /$ Akt-dependent signaling pathway in microglia exposed to $A \beta_{1-42}$ [117]. Some studies also pointed that in APP Tg2576 mice models, melatonin decreased $\mathrm{A} \beta$ burden in young mice but showed no effects on F2-IsoPs or A $\beta$ burden in older plaque-bearing mice $[125,126]$. Taken together, the above evidence suggests that melatonin serves as a potential antioxidant therapeutic strategy for Alzheimer's disease but further clinical trials are still needed to determine the clinical value and efficacy of melatonin in the future.

15.2. Monoamine Oxidase-B Inhibitor. Selegiline (Ldeprenyl) is a selective monoamine oxidase-B inhibitor with possible antioxidant properties and can be used in the treatment of neurodegenerative diseases. It can generate potent vasodilator nitric oxide particularly in cerebral blood vessels rapidly [127]. It may also protect the vascular endothelium from the toxic effects of $A \beta$ peptide and enhance the function of nigral neurons or enhance their survival by inhibiting oxidative deamination [73, 115]. In 1997, Sano et al. reported that in patients with moderately severe impairment from $\mathrm{AD}$, treatment with selegiline (10 $\mathrm{mg}$ a day) reduces neuronal damage and slows the progression $\mathrm{AD}$ [73]. These findings suggest that the use of selegiline may delay clinically important functional deterioration in patients with Alzheimer's disease. Though most of studies have shown that selegiline may bring improvements in cognition, behavior, and mood, little evidence shows a global benefit in cognition, functional ability, and behavior. In 2000, the authors of a meta-analysis of 15 clinical trials concluded that there was not enough evidence to recommend selegiline as a treatment for Alzheimer's disease.

15.3. Estrogen. Estrogen has been shown to act as an antioxidant to protect neurons from the toxicity of $\mathrm{A} \beta$ [115]. 
TABLE 2: Summary of the various antioxidants interventions in cells or animal models of AD and human trials studied for Alzheimer's disease.

\begin{tabular}{|c|c|c|c|c|}
\hline Antioxidant intervention & Cells or animal models of AD & Human trials & Outcome & Reference \\
\hline & $\mathrm{A} \beta$-induced $\mathrm{AD}$ rats model & & $\begin{array}{l}\text { Attenuated toxic effects of } \mathrm{A} \beta \text { and } \\
\text { improved cognitive performance. }\end{array}$ & {$[71]$} \\
\hline & & $\begin{array}{l}\text { Treatment with } \\
\alpha \text {-tocopherol } \\
\text { (2000 IU a day) in } \\
\text { patients with } \\
\text { moderately severe } \\
\text { impairment from AD }\end{array}$ & $\begin{array}{l}\text { Reduced neuronal damage and slowed } \\
\text { progression of AD. }\end{array}$ & {$[73]$} \\
\hline \multirow[t]{4}{*}{ Vitamin E ( $\alpha$-tocopherol) } & APP Tg2576 mice & & $\begin{array}{l}\text { Suppressed brain lipid peroxidation, } \\
\text { reduced } \mathrm{A} \beta \text { levels and senile plaque } \\
\text { deposition, and decreased F2-IsoPs levels. }\end{array}$ & {$[74]$} \\
\hline & $\begin{array}{l}\text { Transgenic mouse models of } \\
\text { human tauopathies and AD }\end{array}$ & & $\begin{array}{l}\text { Suppressed tau-induced neurotoxicity, } \\
\text { decreased carbonyls, and decreased } \\
\text { 8OHdG. }\end{array}$ & {$[74,75]$} \\
\hline & Drosophila & & Suppressed tau-induced neurotoxicity. & {$[76]$} \\
\hline & & $\begin{array}{l}\text { AD patients whose } \\
\text { regimens included } \\
\text { vitamin } \mathrm{E}\end{array}$ & $\begin{array}{l}\text { Longer survival rate than those taking no } \\
\text { drug or a ChEI alone. }\end{array}$ & {$[77]$} \\
\hline Vitamin C & $\begin{array}{l}\text { Methionine diet-induced } \\
\text { hyperhomocysteinemia rats }\end{array}$ & & $\begin{array}{l}\text { Decreased oxidative stress in vivo, } \\
\text { enhanced NO bioavailability, restored } \\
\text { regulation of shear stress in arterioles, } \\
\text { and normalized systemic blood pressure. }\end{array}$ & {$[78]$} \\
\hline \multirow[t]{2}{*}{ vitamin $\mathrm{B}_{12}$} & Cats & & $\begin{array}{l}\text { Increased choline acetyltransferase } \\
\text { activity in cholinergic neurons. }\end{array}$ & {$[88]$} \\
\hline & & AD patients & Improved cognitive functions. & {$[89]$} \\
\hline MnSOD & APP Tg2576 mice & & $\begin{array}{l}\text { Deficiency of MnSOD increases A } \beta \text { levels } \\
\text { and accelerates the onset of behavioral } \\
\text { alteration. }\end{array}$ & {$[92]$} \\
\hline LA $(\alpha$-lipoic acid $)$ & APP Tg2576 mice & & $\begin{array}{l}\text { Decreased expression of lipid } \\
\text { peroxidation markers of oxidative } \\
\text { modification but not } \beta \text {-amyloid load } \\
\text { within the brains; improved performance } \\
\text { in Morris water maze but not effective at } \\
\text { altering cognition in the Y-maze test. }\end{array}$ & {$[96]$} \\
\hline $\begin{array}{l}\text { MitoQ and Szeto Schiller } \\
\text { (SS) peptide } 31\end{array}$ & $\begin{array}{l}\text { APP Tg } 2576 \text { mice and mouse } \\
\text { neuroblastoma }(\mathrm{N} 2 \mathrm{a}) \text { cells } \\
\text { incubated with the } \mathrm{A} \beta \text { peptide }\end{array}$ & & $\begin{array}{l}\text { Prevented } \mathrm{A} \beta \text { toxicity in mitochondria on } \\
\text { neurons. }\end{array}$ & {$[105]$} \\
\hline Caffeine & $\begin{array}{l}\text { Cholesterol-fed rabbit model } \\
\text { system for late onset sporadic } \\
\text { AD }\end{array}$ & & $\begin{array}{l}\text { Decreased A } \beta \text { production and } \\
\text { accumulation, reduced phosphorylation } \\
\text { of tau, attenuated ROS and } 8 \text {-Iso-PGF } 2 \alpha \\
\text { levels, and reduced glutathione depletion, } \\
\text { and protection against } \\
\text { cholesterol-induced ER stress. }\end{array}$ & {$[107]$} \\
\hline Curcumin & APP Tg2576 mice & & $\begin{array}{l}\text { Reduced carbonyls and facilitated } \\
\text { disaggregation of } A \beta \text { and reduction in } \\
\text { AD associated neuropathology. }\end{array}$ & [109] \\
\hline Silibinin & $\begin{array}{l}\text { Aggregated A } \beta_{25-35} \text {-induced } \\
\text { AD model mice }\end{array}$ & & $\begin{array}{l}\text { Prevented memory impairment and } \\
\text { oxidative damage induced by } \mathrm{A} \beta \text {. }\end{array}$ & {$[111]$} \\
\hline \multirow[t]{2}{*}{ Ginkgo biloba } & APP Tg2576 mice & & $\begin{array}{l}\text { Improved cognitive functions but } \\
\text { without any effects on } A \beta \text { levels or senile } \\
\text { plaque. }\end{array}$ & {$[112]$} \\
\hline & & $\begin{array}{l}\text { Postmortem brain } \\
\text { ELISA measurement }\end{array}$ & $\begin{array}{l}\text { No significant effects on senile plaque size } \\
\text { or } A \beta \text { levels. }\end{array}$ & {$[113]$} \\
\hline
\end{tabular}


TABle 2: Continued.

\begin{tabular}{|c|c|c|c|c|}
\hline Antioxidant intervention & Cells or animal models of AD & Human trials & Outcome & Reference \\
\hline \multirow{4}{*}{ Melatonin } & $\begin{array}{l}\text { APP695 transgenic mouse } \\
\text { model }\end{array}$ & & Improved learning and memory deficits. & {$[124]$} \\
\hline & $\begin{array}{l}\text { AD cell models such as mouse } \\
\text { microglial BV2 cells, rat } \\
\text { astroglioma C6 cells, and } \\
\text { PC12 cells }\end{array}$ & & $\begin{array}{l}\text { Attenuated } \mathrm{A} \beta \text {-induced apoptosis, } \\
\text { inhibited } \mathrm{A} \beta \text {-induced } \\
\text { mitochondria-related bax increase. }\end{array}$ & {$[124]$} \\
\hline & Microglia exposed to $A \beta_{1-42}$ & & $\begin{array}{l}\text { Inhibited phosphorylation of NADPH } \\
\text { oxidase via a PI } 3 \text { K/Akt-dependent } \\
\text { signaling pathway. }\end{array}$ & {$[117]$} \\
\hline & APP Tg2576 mice & & $\begin{array}{l}\text { Decreased } \mathrm{A} \beta \text { burden in young mice; no } \\
\text { effects on } \mathrm{F} 2 \text {-IsoPs or } \mathrm{A} \beta \text { burden in older } \\
\text { plaque-bearing mice. }\end{array}$ & {$[125,126]$} \\
\hline Selegiline (L-deprenyl) & & $\begin{array}{l}\text { Treatment with } \\
\text { selegiline ( } 10 \mathrm{mg} \text { a } \\
\text { day) in patients with } \\
\text { moderately severe } \\
\text { impairment from AD }\end{array}$ & $\begin{array}{l}\text { Reduced neuronal damage and slowed } \\
\text { progression of AD. }\end{array}$ & [73] \\
\hline
\end{tabular}

AD: Alzheimer's disease; 8OHdG: 8-hydroxy-2-deoxyguanosine; ChEI: cholinesterase inhibitors.

Although estrogen may have a neuroprotective effect [128], it does not appear to improve cognition or function in patients with Alzheimer's disease [129]. At present, there is no evidence that supports recommending the use of estrogen as an antioxidant to decrease the risk of $\mathrm{AD}$ or the progression of existing $\mathrm{AD}$, therefore, further studies need to be conducted to determine if treatment with estrogen may prevent or delay the onset of $\mathrm{AD}$ or reduce its severity [115].

The various antioxidants interventions in cells or animal models of $\mathrm{AD}$ and human trials studied for Alzheimer's disease are summarized in Table 2.

\section{Summary}

Alzheimer's disease is recognized as a chronic neurodegenerative condition with a long asymptomatic period prior to recognizable clinical dementia. Multiple lines of evidence have shown strong implications that oxidative stress or damage plays essential roles in the pathogenesis of several neurodegenerative diseases such as $\mathrm{AD}$ through a number of mechanisms including oxidative damages caused by free radicals which may result in neuronal cell death. AD mice models show that increased oxidative damage is a relatively early event in the pathogenesis of AD that may be suppressed by antioxidants. Therefore, the development of approaches to prevent or reduce oxidative damages may provide therapeutic efficacy, and antioxidants have been identified as parts of these therapeutic strategies for Alzheimer's disease.

Metabolic antioxidants, mitochondria-directed antioxidants, and SS peptides have proved to be effective in $\mathrm{AD}$ mouse models and small clinical studies. It has also been shown that treatment with antioxidants vitamin $\mathrm{E}$, vitamin C, selegiline, estrogen, Ginkgo biloba, and so forth may exert certain positive effects on the development of $\mathrm{AD}$, but the efficacy of those antioxidants in clinical patients is still controversial and not so conclusive. Most antioxidant drugs show general success in animal models but less beneficial in human trials; clinical trials for $\mathrm{AD}$ prevention and treatment by antioxidants are still in their infancy. Therefore, further studies will be quite necessary to determine if antioxidants may decrease the risk or slow the progression of the disease for $\mathrm{AD}$ patients.

\section{Acknowledgments}

This work was supported in part by Grants from National Natural Science Foundation of China (31071226), Education Ministry of China (NCET-07-0332), and Fundamental Research Funds for the Central Universities (HUST 2010MS036 and 2011TS128).

\section{References}

[1] R. J. Castellani, R. K. Rolston, and M. A. Smith, "Alzheimer disease," Disease-a-Month, vol. 56, no. 9, pp. 484-546, 2010.

[2] R. N. Kalaria, G. E. Maestre, R. Arizaga et al., "Alzheimer's disease and vascular dementia in developing countries: prevalence, management, and risk factors," The Lancet Neurology, vol. 7, no. 9, pp. 812-826, 2008.

[3] V. Wilquet and B. D. Strooper, "Amyloid-beta precursor protein processing in neurodegeneration," Current Opinion in Neurobiology, vol. 14, no. 5, pp. 582-588, 2004.

[4] M. Roth, B. E. Tomlinson, and G. Blessed, "Correlation between scores for dementia and counts of "senile plaques" in cerebral grey matter of elderly subjects," Nature, vol. 209, no. 5018, pp. 109-110, 1966.

[5] M. Roth, B. E. Tomlinson, and G. Blessed, "The relationship between quantitative measures of dementia and of degenerative changes in the cerebral grey matter of elderly subjects," Proceedings of the Royal Society of Medicine, vol. 60, no. 3, pp. 254-260, 1967.

[6] B. E. Tomlinson, G. Blessed, and M. Roth, "Observations on the brains of demented old people," Journal of the Neurological Sciences, vol. 11, no. 3, pp. 205-242, 1970. 
[7] W. S. Brooks, J. B. J. Kwok, J. J. Kril et al., “Alzheimer’s disease with spastic paraparesis and "cotton wool" plaques: two pedigrees with PS-1 exon 9 deletions," Brain, vol. 126, no. 4, pp. 783-791, 2003.

[8] J. C. Janssen, P. L. Lantos, N. C. Fox et al., "Autopsyconfirmed familial early-onset Alzheimer disease caused by the L153V presenilin 1 mutation," Archives of Neurology, vol. 58, no. 6, pp. 953-958, 2001.

[9] M. Mancuso, D. Orsucci, G. Siciliano, and L. Murri, "Mitochondria, mitochondrial DNA and Alzheimer's disease. What comes first?" Current Alzheimer Research, vol. 5, no. 5, pp. 457-468, 2008.

[10] D. W. Dickson, H. A. Crystal, L. A. Mattiace et al., "Identification of normal and pathological aging in prospectively studied nondemented elderly humans," Neurobiology of Aging, vol. 13, no. 1, pp. 179-189, 1992.

[11] W. J. Strittmatter and A. D. Roses, "Apolipoprotein E and Alzheimer's disease," Proceedings of the National Academy of Sciences of the United States of America, vol. 92, no. 11, pp. 4725-4727, 1995.

[12] L. E. Hebert, P. A. Scherr, L. A. Beckett et al., "Agespecific incidence of Alzheimer's disease in a community population," Journal of the American Medical Association, vol. 273, no. 17, pp. 1354-1359, 1995.

[13] C. W. Zhu and M. Sano, "Economic considerations in the management of Alzheimer's disease," Clinical Interventions in Aging, vol. 1, no. 2, pp. 143-154, 2006.

[14] M. A. Smith, P. L. Richey Harris, L. M. Sayre, J. S. Beckman, and G. Perry, "Widespread peroxynitrite-mediated damage in Alzheimer's disease," Journal of Neuroscience, vol. 17, no. 8, pp. 2653-2657, 1997.

[15] R. N. Kalaria, "Microglia and Alzheimer's disease," Current Opinion in Hematology, vol. 6, no. 1, pp. 15-24, 1999.

[16] J. S. Braun, J. E. Sublett, D. Freyer et al., "Pneumococcal pneumolysin and $\mathrm{H}_{2} \mathrm{O}_{2}$ mediate brain cell apoptosis during meningitis," Journal of Clinical Investigation, vol. 109, no. 1, pp. 19-27, 2002.

[17] B. Hempen and J. P. Brion, "Reduction of acetylated $\alpha$ tubulin immunoreactivity in neurofibrillary tangle-bearing neurons in Alzheimer's disease," Journal of Neuropathology and Experimental Neurology, vol. 55, no. 9, pp. 964-972, 1996.

[18] D. M. Walsh and D. J. Selkoe, "A $\beta$ oligomers - a decade of discovery," Journal of Neurochemistry, vol. 101, no. 5, pp. 1172-1184, 2007.

[19] R. J. Castellani, H. G. Lee, X. Zhu, G. Perry, and M. A. Smith, "Alzheimer disease pathology as a host response," Journal of Neuropathology and Experimental Neurology, vol. 67, no. 6, pp. 523-531, 2008.

[20] C. Brayne, K. Richardson, F. E. Matthews et al., "Neuropathological correlates of dementia in over-80-year-old brain donors from the population-based Cambridge city over-75s cohort (CC75C) study," Journal of Alzheimer's Disease, vol. 18, no. 3, pp. 645-658, 2009.

[21] A. Nunomura, R. J. Castellani, X. Zhu, P. I. Moreira, G. Perry, and M. A. Smith, "Involvement of oxidative stress in Alzheimer disease," Journal of Neuropathology and Experimental Neurology, vol. 65, no. 7, pp. 631-641, 2006.

[22] D. Harman, "The aging process," Proceedings of the National Academy of Sciences of the United States of America, vol. 78, no. 11, pp. 7124-7128, 1981.

[23] H. A. Jung, B. S. Min, T. Yokozawa, J. H. Lee, Y. S. Kim, and J. S. Choi, "Anti-Alzheimer and antioxidant activities of coptidis rhizoma alkaloids," Biological and Pharmaceutical Bulletin, vol. 32, no. 8, pp. 1433-1438, 2009.

[24] B. P. Yu, "Cellular defenses against damage from reactive oxygen species," Physiological Reviews, vol. 74, no. 1, pp. 139$162,1994$.

[25] M. A. Lovell and W. R. Markesbery, "Oxidative DNA damage in mild cognitive impairment and late-stage Alzheimer's disease," Nucleic Acids Research, vol. 35, no. 22, pp. 74977504, 2007.

[26] D. Pratico, C. M. Clark, V. M. Lee, J. Q. Trojanowski, J. Rokach, and G. A. Fitz-Gerald, "Increased 8,12-iso-iPF2 $\alpha$-VI in Alzheimer's disease: correlation of a noninvasive index of lipid peroxidation with disease severity," Annals of Neurology, vol. 48, pp. 809-812, 2000.

[27] P. J. Thornalley, "Glutathione-dependent detoxification of $\alpha$ oxoaldehydes by the glyoxalase system: involvement in disease mechanisms and antiproliferative activity of glyoxalase I inhibitors," Chemico-Biological Interactions, vol. 111-112, pp. 137-151, 1998.

[28] A. N. Donahue, M. Aschner, L. H. Lash, T. Syversen, and W. E. Sonntag, "Growth hormone administration to aged animals reduces disulfide glutathione levels in hippocampus," Mechanisms of Ageing and Development, vol. 127, no. 1, pp. 57-63, 2006.

[29] Y. Zhu, P. M. Carvey, and Z. Ling, "Age-related changes in glutathione and glutathione-related enzymes in rat brain," Brain Research, vol. 1090, no. 1, pp. 35-44, 2006.

[30] P. Mecocci, U. MacGarvey, and M. F. Beal, "Oxidative damage to mitochondrial DNA is increased in Alzheimer's disease," Annals of Neurology, vol. 36, no. 5, pp. 747-751, 1994.

[31] K. Hensley, N. Hall, R. Subramaniam et al., "Brain regional correspondence between Alzheimer's disease histopathology and biomarkers of protein oxidation," Journal of Neurochemistry, vol. 65, no. 5, pp. 2146-2156, 1995.

[32] C. Ramassamy, P. Krzywokowski, and S. Bastianetto, "Apolipoprotein E, oxidative stress and EGb 761 in Alzheimer's disease brain," in Ginkgo Biloba Extract (EGb 761) Study: Lesson from Cell Biology, L. Packer and Y. Christen, Eds., pp. 69-83, Elsevier, Paris, Farnce, 1998.

[33] S. D. Yan, X. Chen, A. M. Schmidt et al., "Glycated tau protein in Alzheimer disease: a mechanism for induction of oxidant stress," Proceedings of the National Academy of Sciences of the United States of America, vol. 91, no. 16, pp. 7787-7791, 1994.

[34] P. F. Good, P. Werner, A. Hsu, C. W. Olanow, and D. P. Perl, "Evidence for neuronal oxidative damage in Alzheimer's disease," American Journal of Pathology, vol. 149, pp. 21-28, 1996.

[35] M. A. Smith, G. Perry, P. L. Richey et al., "Oxidative damage in Alzheimer's," Nature, vol. 382, no. 6587, pp. 120-121, 1996.

[36] M. A. Pappolla, R. A. Omar, K. S. Kim, and N. K. Robakis, "Immunohistochemical evidence of antioxidant stress in Alzheimer's disease," American Journal of Pathology, vol. 140, no. 3, pp. 621-628, 1992.

[37] H. M. Schipper, S. Cissé, and E. G. Stopa, "Expression of heme oxygenase-1 in the senescent and Alzheimer-diseased brain," Annals of Neurology, vol. 37, no. 6, pp. 758-768, 1995.

[38] W. R. Markesbery, "Oxidative stress hypothesis in Alzheimer's disease," Free Radical Biology and Medicine, vol. 23, no. 1, pp. 134-147, 1997.

[39] M. L. Selley, D. R. Close, and S. E. Stern, "The effect of increased concentrations of homocysteine on the concentration of (E)-4-hydroxy-2-nonenal in the plasma and 
cerebrospinal fluid of patients with Alzheimer's disease," Neurobiology of Aging, vol. 23, no. 3, pp. 383-388, 2002.

[40] T. J. Montine, W. R. Markesbery, J. D. Morrow, and L. J. Roberts, "Cerebrospinal fluid F2-isoprostane levels are increased in Alzheimer's disease," Annals of Neurology, vol. 44, no. 3, pp. 410-413, 1998.

[41] J. Busciglio and B. A. Yankner, "Apoptosis and increased generation of reactive oxygen species in Down's syndrome neurons in vitro," Nature, vol. 378, no. 6559, pp. 776-779, 1995.

[42] A. Nunomura, G. Perry, G. Aliev et al., "Oxidative damage is the earliest event in Alzheimer disease," Journal of Neuropathology and Experimental Neurology, vol. 60, no. 8, pp. 759-767, 2001.

[43] C. R. Harrington and C. A. L. S. Colaco, "A glycation connection," Nature, vol. 370, no. 6487, pp. 247-248, 1994.

[44] M. Prabhakaram and B. J. Ortwerth, "Determination of glycation crosslinking by the sugar-dependent incorporation of $\left[{ }^{14} \mathrm{C}\right]$ lysine into protein," Analytical Biochemistry, vol. 216, no. 2, pp. 305-312, 1994.

[45] Y. M. Li and D. W. Dickson, "Enhanced binding of advanced glycation endproducts (AGE) by the ApoE4 isoform links the mechanism of plaque deposition in Alzheimer's disease," Neuroscience Letters, vol. 226, no. 3, pp. 155-158, 1997.

[46] C. González, G. Farías, and R. B. Maccioni, "Modification of tau to an Alzheimer's type protein interferes with its interaction with microtubules," Cellular and Molecular Biology, vol. 44, no. 7, pp. 1117-1127, 1998.

[47] J. El Khoury, S. E. Hickman, C. A. Thomas, L. Cao, S. C. Silverstein, and J. D. Loike, "Scavenger receptor-mediated adhesion of microglia to $\beta$-amyloid fibrils," Nature, vol. 382, no. 6593, pp. 716-719, 1996.

[48] R. Castellani, K. Hirai, G. Aliev et al., "Role of mitochondrial dysfunction in Alzheimer's disease," Journal of Neuroscience Research, vol. 70, no. 3, pp. 357-360, 2002.

[49] D. A. Cottrell, E. L. Blakely, M. A. Johnson, P. G. Ince, and D. M. Turnbull, "Mitochondrial enzyme-deficient hippocampal neurons and choroidal cells in AD," Neurology, vol. 57, no. 2, pp. 260-264, 2001.

[50] E. M. Mutisya, A. C. Bowling, and M. F. Beal, "Cortical cytochrome oxidase activity is reduced in Alzheimer's disease," Journal of Neurochemistry, vol. 63, no. 6, pp. 21792184, 1994.

[51] W. D. Parker and J. K. Parks, "Cytochrome c oxidase in Alzheimer's disease brain: purification and characterization," Neurology, vol. 45, no. 3, pp. 482-486, 1995.

[52] K. Hirai, G. Aliev, A. Nunomura et al., "Mitochondrial abnormalities in Alzheimer's disease," Journal of Neuroscience, vol. 21, no. 9, pp. 3017-3023, 2001.

[53] X. Zhu, M. A. Smith, G. Perry, and G. Aliev, "Mitochondrial failures in Alzheimer's disease," American Journal of Alzheimer's Disease and other Dementias, vol. 19, no. 6, pp. 345-352, 2004.

[54] M. F. Beal, "Mitochondria, free radicals, and neurodegeneration," Current Opinion in Neurobiology, vol. 6, no. 5, pp. 661666, 1996.

[55] M. Manczak, T. S. Anekonda, E. Henson, B. S. Park, J. Quinn, and P. H. Reddy, "Mitochondria are a direct site of $\mathrm{A} \beta$ accumulation in Alzheimer's disease neurons: implications for free radical generation and oxidative damage in disease progression," Human Molecular Genetics, vol. 15, no. 9, pp. 1437-1449, 2006.
[56] P. H. Reddy, S. McWeeney, B. S. Park et al., "Gene expression profiles of transcripts in amyloid precursor protein transgenic mice: up-regulation of mitochondrial metabolism and apoptotic genes is an early cellular change in Alzheimer's disease," Human Molecular Genetics, vol. 13, no. 12, pp. 12251240, 2004.

[57] E. L. Streck, C. Matté, P. S. Vieira et al., "Impairment of energy metabolism in hippocampus of rats subjected to chemically-induced hyperhomocysteinemia," Biochimica et Biophysica Acta, vol. 1637, no. 3, pp. 187-192, 2003.

[58] S. Chang, T. R. Ma, R. D. Miranda, M. E. Balestra, R. W. Mahley, and Y. Huang, "Lipid- and receptor-binding regions of apolipoprotein E4 fragments act in concert to cause mitochondrial dysfunction and neurotoxicity," Proceedings of the National Academy of Sciences of the United States of America, vol. 102, no. 51, pp. 18694-18699, 2005.

[59] H. B. Staehelin, "Micronutrients and Alzheimer's disease," Proceedings of the Nutrition Society, vol. 64, no. 4, pp. 565570, 2005.

[60] M. Grundman, "Vitamin E and Alzheimer's disease: the basis for additional clinical trials," American Journal of Clinical Nutrition, vol. 71, pp. 630-636, 2000.

[61] J. Neuzil, B. A. Darlow, T. E. Inder, K. B. Sluis, C. C. Winterbourn, and R. Stocker, "Oxidation of parenteral lipid emulsion by ambient and phototherapy lights: potential toxicity of routine parenteral feeding," Journal of Pediatrics, vol. 126, no. 5, pp. 785-790, 1995.

[62] R. Stocker, "Lipoprotein oxidation: mechanistic aspects, methodological approaches and clinical relevance," Current Opinion in Lipidology, vol. 5, no. 6, pp. 422-433, 1994.

[63] V. W. Bowry and R. Stocker, "Tocopherol-mediated peroxidation. The prooxidant effect of vitamin $\mathrm{E}$ on the radicalinitiated oxidation of human low-density lipoprotein," Journal of the American Chemical Society, vol. 115, no. 14, pp. 6029-6044, 1993.

[64] A. Kontush, B. Finckh, B. Karten, A. Kohlschütter, and U. Beisiegel, "Antioxidant and prooxidant activity of $\alpha$ tocopherol in human plasma and low density lipoprotein," Journal of Lipid Research, vol. 37, no. 7, pp. 1436-1448, 1996.

[65] A. Kontush and S. Schekatolina, "Vitamin E in neurodegenerative disorders: Alzheimer's disease," Annals of the New York Academy of Sciences, vol. 1031, pp. 249-262, 2004.

[66] M. M. Berger, "Can oxidative damage be treated nutritionally?" Clinical Nutrition, vol. 24, no. 2, pp. 172-183, 2005.

[67] A. Terada, M. Yoshida, Y. Seko et al., "Active oxygen species generation and cellular damage by additives of parenteral preparations: selenium and sulfhydryl compounds," Nutrition, vol. 15, no. 9, pp. 651-655, 1999.

[68] Y. K. Nakamura, M. H. Read, J. W. Elias, and S. T. Omaye, "Oxidation of serum low-density lipoprotein (LDL) and antioxidant status in young and elderly humans," Archives of Gerontology and Geriatrics, vol. 42, no. 3, pp. 265-276, 2006.

[69] M. Dumont, M. T. Lin, and M. F. Beal, "Mitochondria and antioxidant targeted therapeutic strategies for Alzheimer's disease," Journal of Alzheimer's Disease, vol. 20, no. 2, pp. S633-S643, 2010.

[70] C. J. Foy, A. P. Passmore, M. D. Vahidassr, I. S. Young, and J. T. Lawson, "Plasma chain-breaking antioxidants in Alzheimer's disease, vascular dementia and Parkinson's disease," An International Journal of Medicine, vol. 92, no. 1, pp. 39-45, 1999.

[71] T. Montiel, R. Quiroz-Baez, L. Massieu, and C. Arias, "Role of oxidative stress on $\beta$-amyloid neurotoxicity elicited during impairment of energy metabolism in the hippocampus: 
protection by antioxidants," Experimental Neurology, vol. 200, no. 2, pp. 496-508, 2006.

[72] E. E. Devore, F. Grodstein, F. J. A. van Rooij et al., "Dietary antioxidants and long-term risk of dementia," Archives of Neurology, vol. 67, no. 7, pp. 819-825, 2010.

[73] M. Sano, C. Ernesto, R. G. Thomas et al., "A controlled trial of selegiline, alpha-tocopherol, or both as treatment for Alzheimer's disease," The New England Journal of Medicine, vol. 336, no. 17, pp. 1216-1222, 1997.

[74] S. Sung, Y. Yao, K. Uryu et al., "Early vitamin E supplementation in young but not aged mice reduces Abeta levels and amyloid deposition in a transgenic model of Alzheimer's disease," The FASEB Journal, vol. 18, no. 2, pp. 323-325, 2004.

[75] H. Nakashima, T. Ishihara, O. Yokota et al., "Effects of $\alpha$ tocopherol on an animal model of tauopathies," Free Radical Biology and Medicine, vol. 37, no. 2, pp. 176-186, 2004.

[76] D. Dias-Santagata, T. A. Fulga, A. Duttaroy, and M. B. Feany, "Oxidative stress mediates tau-induced neurodegeneration in Drosophila," Journal of Clinical Investigation, vol. 117, no. 1, pp. 236-245, 2007.

[77] V. N. Pavlik, R. S. Doody, S. D. Rountree, and E. J. Darby, "Vitamin E use is associated with improved survival in an Alzheimer's disease cohort," Dementia and Geriatric Cognitive Disorders, vol. 28, no. 6, pp. 536-540, 2009.

[78] Z. Bagi, C. Csekó, E. Tóth, and A. Koller, "Oxidative stressinduced dysregulation of arteriolar wall shear stress and blood pressure in hyperhomocysteinemia is prevented by chronic vitamin C treatment," American Journal of Physiology, vol. 285, no. 6, pp. H2277-H2283, 2003.

[79] D. Fusco, G. Colloca, M. R. Lo Monaco, and M. Cesari, "Effects of antioxidant supplementation on the aging process," Clinical Interventions in Aging, vol. 2, no. 3, pp. 377387, 2007.

[80] J. E. Upritchard, C. R. W. C. Schuurman, A. Wiersma et al., "Spread supplemented with moderate doses of vitamin $\mathrm{E}$ and carotenoids reduces lipid peroxidation in healthy, nonsmoking adults," American Journal of Clinical Nutrition, vol. 78, no. 5, pp. 985-992, 2003.

[81] P. Di Mascio, M. E. Murphy, and H. Sies, "Antioxidant defense systems: the role of carotenoids, tocopherols, and thiols," American Journal of Clinical Nutrition, vol. 53, no. 1, pp. 194S-200S, 1991.

[82] E. Niki, N. Noguchi, H. Tsuchihashi, and N. Gotoh, "Interaction among vitamin $\mathrm{C}$, vitamin $\mathrm{E}$, and $\beta$-carotene," American Journal of Clinical Nutrition, vol. 62, no. 6, pp. 1322S-1326S, 1995.

[83] A. Lloret, M. C. Badía, N. J. Mora, F. V. Pallardó, M. D. Alonso, and J. Viña, "Vitamin e paradox in alzheimer's disease: it does not prevent loss of cognition and may even be detrimental," Journal of Alzheimer's Disease, vol. 17, no. 1, pp. 143-149, 2009.

[84] C. D. Kamat, S. Gadal, M. Mhatre, K. S. Williamson, Q. N. Pye, and K. Hensley, "Antioxidants in central nervous system diseases: preclinical promise and translational challenges," Journal of Alzheimer's Disease, vol. 15, no. 3, pp. 473-493, 2008.

[85] M. C. Morris, D. A. Evans, J. L. Bienias et al., "Dietary intake of antioxidant nutrients and the risk of incident Alzheimer disease in a biracial community study," Journal of the American Medical Association, vol. 287, no. 24, pp. 32303237, 2002.

[86] G. J. Brewer, "Why vitamin e therapy fails for treatment of Alzheimer's disease," Journal of Alzheimer's Disease, vol. 19, no. 1, pp. 27-30, 2010.
[87] B. Regland, C. G. Gottfries, and L. Oreland, "Vitamin B12induced reduction of platelet monoamine oxidase activity in patients with dementia and pernicious anaemia," European Archives of Psychiatry and Clinical Neuroscience, vol. 240, no. 4-5, pp. 288-291, 1991.

[88] A. Nadeau and A. G. Roberge, "Effects of vitamin B12 supplementation on choline acetyltransferase activity in cat brain," International Journal for Vitamin and Nutrition Research, vol. 58, no. 4, pp. 402-406, 1988.

[89] T. Ikeda, K. Yamamoto, K. Takahashi et al., "Treatment of Alzheimer-type dementia with intravenous mecobalamin," Clinical Therapeutics, vol. 14, no. 3, pp. 426-437, 1992.

[90] D. L. Marcus, C. Thomas, C. Rodriguez et al., "Increased peroxidation and reduced antioxidant enzyme activity in Alzheimer's disease," Experimental Neurology, vol. 150, no. 1, pp. 40-44, 1998.

[91] M. Gonzalez-Zulueta, L. M. Ensz, G. Mukhina et al., "Manganese superoxide dismutase protects nNOS neurons from NMDA and nitric oxide-mediated neurotoxicity," Journal of Neuroscience, vol. 18, no. 6, pp. 2040-2055, 1998.

[92] L. Esposito, J. Raber, L. Kekonius et al., "Reduction in mitochondrial superoxide dismutase modulates Alzheimer's disease-like pathology and accelerates the onset of behavioral changes in human amyloid precursor protein transgenic mice," Journal of Neuroscience, vol. 26, no. 19, pp. 5167-5179, 2006.

[93] X. Wang, B. Su, H. Fujioka, and X. Zhu, "Dynamin-like protein 1 reduction underlies mitochondrial morphology and distribution abnormalities in fibroblasts from sporadic Alzheimer's disease patients," American Journal of Pathology, vol. 173, no. 2, pp. 470-482, 2008.

[94] S. L. Siedlak, G. Casadesus, K. M. Webber et al., "Chronic antioxidant therapy reduces oxidative stress in a mouse model of Alzheimer's disease," Free Radical Research, vol. 43, no. 2, pp. 156-164, 2009.

[95] X. Zhu, A. K. Raina, G. Perry, and M. A. Smith, "Alzheimer's disease: the two-hit hypothesis," The Lancet Neurology, vol. 3, no. 4, pp. 219-226, 2004.

[96] J. F. Quinn, J. R. Bussiere, R. S. Hammond et al., "Chronic dietary $\alpha$-lipoic acid reduces deficits in hippocampal memory of aged Tg2576 mice," Neurobiology of Aging, vol. 28, no. 2, pp. 213-225, 2007.

[97] E. Niki, "Mechanisms and dynamics of antioxidant action of ubiquinol," Molecular Aspects of Medicine, vol. 18, pp. S63S70, 1997.

[98] R. S. Chen, C. C. Huang, and N. S. Chu, "Coenzyme Q10 treatment in mitochondrial encephalomyopathies. Shortterm double-blind, crossover study," European Neurology, vol. 37, no. 4, pp. 212-218, 1997.

[99] J. G. Birkmayer, "Coenzyme nicotinamide adenine dinucleotide. New therapeutic approach for improving dementia of the Alzheimer type," Annals of Clinical and Laboratory Science, vol. 26, no. 1, pp. 1-9, 1996.

[100] M. P. Murphy and R. A. J. Smith, "Drug delivery to mitochondria: the key to mitochondrial medicine," Advanced Drug Delivery Reviews, vol. 41, no. 2, pp. 235-250, 2000.

[101] A. M. James, M. S. Sharpley, A. R. B. Manas et al., "Interaction of the mitochondria-targeted antioxidant MitoQ with phospholipid bilayers and ubiquinone oxidoreductases," Journal of Biological Chemistry, vol. 282, no. 20, pp. 1470814718, 2007.

[102] C. Lu, D. Zhang, M. Whiteman, and J. S. Armstrong, "Is antioxidant potential of the mitochondrial targeted ubiquinone derivative MitoQ conserved in cells lacking 
mtDNA?" Antioxidants and Redox Signaling, vol. 10, no. 3, pp. 651-660, 2008.

[103] P. I. Moreira, S. L. Siedlak, X. Wang et al., "Autophagocytosis of mitochondria is prominent in Alzheimer disease," Journal of Neuropathology and Experimental Neurology, vol. 66, no. 7, p. $674,2007$.

[104] P. I. Moreira, X. Zhu, X. Wang et al., "Mitochondria: a therapeutic target in neurodegeneration," Biochimica et Biophysica Acta, vol. 1802, no. 1, pp. 212-220, 2010.

[105] M. Manczak, P. Mao, M. Calkins et al., "Mitochondriatargeted antioxidants protects against Abeta toxicity in Alzheimer's disease neurons," Journal of Alzheimer Disease, vol. 20, supplement 2, pp. S609-S631, 2010.

[106] K. Rezai-Zadeh, D. Shytle, N. Sun et al., "Green tea epigallocatechin-3-gallate (EGCG) modulates amyloid precursor protein cleavage and reduces cerebral amyloidosis in Alzheimer transgenic mice," Journal of Neuroscience, vol. 25, no. 38, pp. 8807-8814, 2005.

[107] J. R. P. Prasanthi, B. Dasari, G. Marwarha et al., "Caffeine protects against oxidative stress and Alzheimer's disease-like pathology in rabbit hippocampus induced by cholesterolenriched diet," Free Radical Biology and Medicine, vol. 49, no. 7, pp. 1212-1220, 2010.

[108] H. P. Ammon, N. Safayhi, T. Mack, and J. Sabieraj, "Mechanism of antiinflammatory actions of curcumine and boswellic acids," Journal of Ethnopharmacology, vol. 38, no. 2-3, pp. 113-119, 1993.

[109] G. P. Lim, T. Chu, F. Yang, W. Beech, S. A. Frautschy, and G. M. Cole, "The curry spice curcumin reduces oxidative damage and amyloid pathology in an Alzheimer transgenic mouse," Journal of Neuroscience, vol. 21, no. 21, pp. 83708377, 2001.

[110] J. Wang, L. Ho, W. Qin et al., "Caloric restriction attenuates $\beta$-amyloid neuropathology in a mouse model of Alzheimer's disease," The FASEB Journal, vol. 19, no. 6, pp. 659-661, 2005.

[111] P. Lu, T. Mamiya, L. L. Lu et al., "Silibinin prevents amyloid b peptide-induced memory impairment and oxidative stress in mice," British Journal of Pharmacology, vol. 157, no. 7, pp. 1270-1277, 2009.

[112] R. W. Stackman, F. Eckenstein, B. Frei, D. Kulhanek, J. Nowlin, and J. F. Quinn, "Prevention of age-related spatial memory deficits in a transgenic mouse model of Alzheimer's disease by chronic Ginkgo biloba treatment," Experimental Neurology, vol. 184, no. 1, pp. 510-520, 2003.

[113] M. Garcia-Alloza, L. A. Borrelli, B. T. Hyman, and B. J. Bacskai, "Antioxidants have a rapid and long-lasting effect on neuritic abnormalities in APP:PS1 mice," Neurobiology of Aging, vol. 31, no. 12, pp. 2058-2068, 2010.

[114] S. Galluzzi, O. Zanetti, G. Binetti, M. Trabucchi, and G. B. Frisoni, "Coma in a patient with Alzheimer's disease taking low dose trazodone and ginkgo biloba," Journal of Neurology Neurosurgery and Psychiatry, vol. 68, no. 5, pp. 679-680, 2000.

[115] E. E. Tuppo and L. J. Forman, "Free radical oxidative damage and Alzheimer's disease," Journal of the American Osteopathic Association, vol. 101, no. 12, supplement 1, pp. S11-S15, 2001.

[116] S. Nishida, "Metabolic effects of melatonin on oxidative stress and diabetes mellitus," Endocrine, vol. 27, no. 2, pp. 131-135, 2005.

[117] J. Zhou, S. Zhang, X. Zhao, and T. Wei, "Melatonin impairs $\mathrm{NADPH}$ oxidase assembly and decreases superoxide anion production in microglia exposed to amyloid- $\beta 1-42$," Journal of Pineal Research, vol. 45, no. 2, pp. 157-165, 2008.
[118] Y. Q. Deng, G. G. Xu, P. Duan, Q. Zhang, and J. Z. Wang, "Effects of melatonin on wortmannin-induced tau hyperphosphorylation," Acta Pharmacologica Sinica, vol. 26, no. 5, pp. 519-526, 2005.

[119] J. Z. Wang and Z. F. Wang, "Role of melatonin in Alzheimerlike neurodegeneration," Acta Pharmacologica Sinica, vol. 27, no. 1, pp. 41-49, 2006.

[120] S. J. Liu and J. Z. Wang, "Alzheimer-like tau phosphorylation induced by wortmannin in vivo and its attenuation by melatonin," Acta Pharmacologica Sinica, vol. 23, no. 2, pp. 183-187, 2002.

[121] D. L. Wang, Z. Q. Ling, F. Y. Cao, L. Q. Zhu, and J. Z. Wang, "Melatonin attenuates isoproterenol-induced protein kinase A overactivation and tau hyperphosphorylation in rat brain," Journal of Pineal Research, vol. 37, no. 1, pp. 11-16, 2004.

[122] X. C. Wang, J. Zhang, X. Yu et al., "Prevention of isoproterenol-induced tau hyperphosphorylation by melatonin in the rat," Sheng Li Xue Bao, vol. 57, pp. 7-12, 2005.

[123] X. C. Li, Z. F. Wang, J. X. Zhang, Q. Wang, and J. Z. Wang, "Effect of melatonin on calyculin A-induced tau hyperphosphorylation," European Journal of Pharmacology, vol. 510, no. 1-2, pp. 25-30, 2005.

[124] Z. Feng and J. T. Zhang, "Protective effect of melatonin on $\beta$ amyloid-induced apoptosis in rat astroglioma c6 cells and its mechanism," Free Radical Biology and Medicine, vol. 37, no. 11, pp. 1790-1801, 2004.

[125] E. Matsubara, T. Bryant-Thomas, J. P. Quinto et al., "Melatonin increases survival and inhibits oxidative and amyloid pathology in a transgenic model of Alzheimer's disease," Journal of Neurochemistry, vol. 85, no. 5, pp. 1101-1108, 2003.

[126] J. Quinn, D. Kulhanek, J. Nowlin et al., "Chronic melatonin therapy fails to alter amyloid burden or oxidative damage in old Tg2576 mice: implications for clinical trials," Brain Research, vol. 1037, no. 1-2, pp. 209-213, 2005.

[127] T. Thomas, "Monamine oxidase-B inhibitors in the treatment of Alzheimer's disease," Neurobiology of Aging, vol. 21, pp. 343-348, 2000.

[128] Y. Goodman, A. J. Bruce, B. Cheng, and M. P. Mattson, "Estrogens attenuate and corticosterone exacerbates excitotoxicity, oxidative injury, and amyloid $\beta$-peptide toxicity in hippocampal neurons," Journal of Neurochemistry, vol. 66, no. 5, pp. 1836-1844, 1996.

[129] R. A. Mulnard, C. W. Cotman, C. Kawas et al., "Estrogen replacement therapy for treatment of mild to moderate Alzheimer disease: a randomized controlled trial. Alzheimer's Disease Cooperative Study," Journal of the American Medical Association, vol. 283, no. 8, pp. 1007-1015, 2000. 


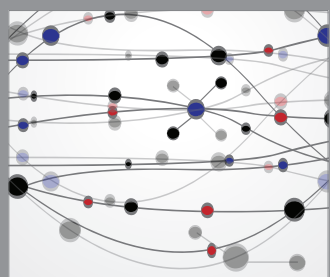

The Scientific World Journal
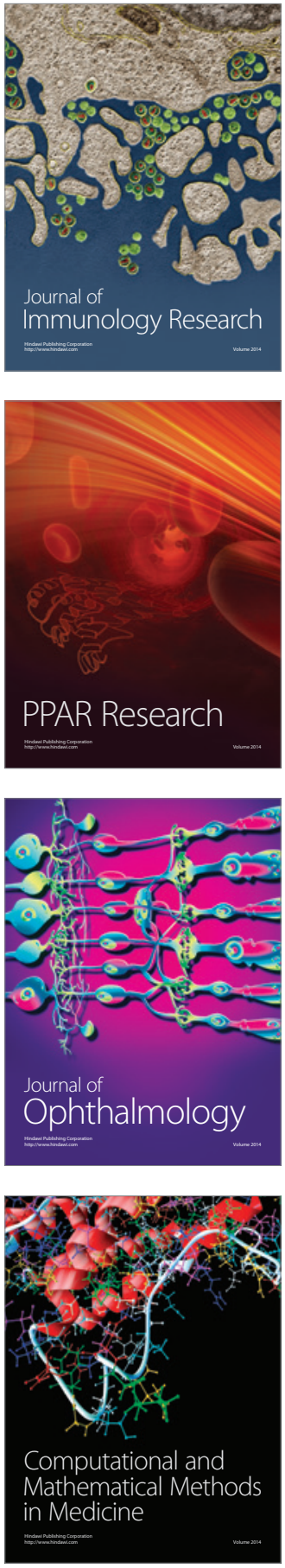



Gastroenterology

Research and Practice
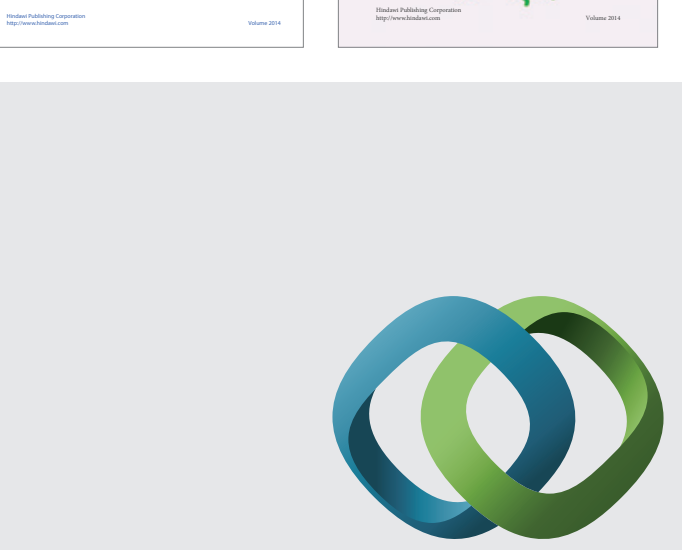

\section{Hindawi}

Submit your manuscripts at

http://www.hindawi.com
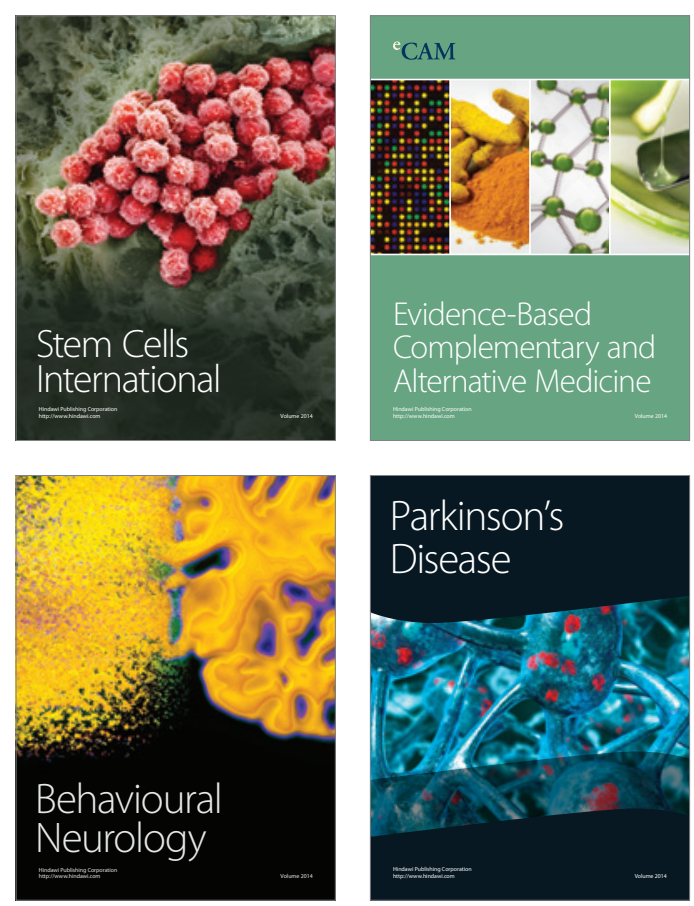



Journal of
Diabetes Research

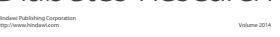

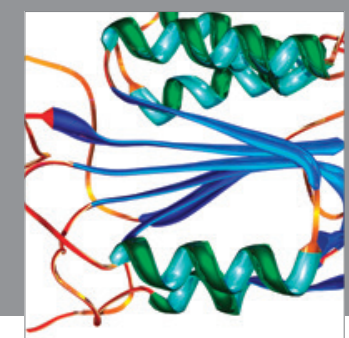

Disease Markers
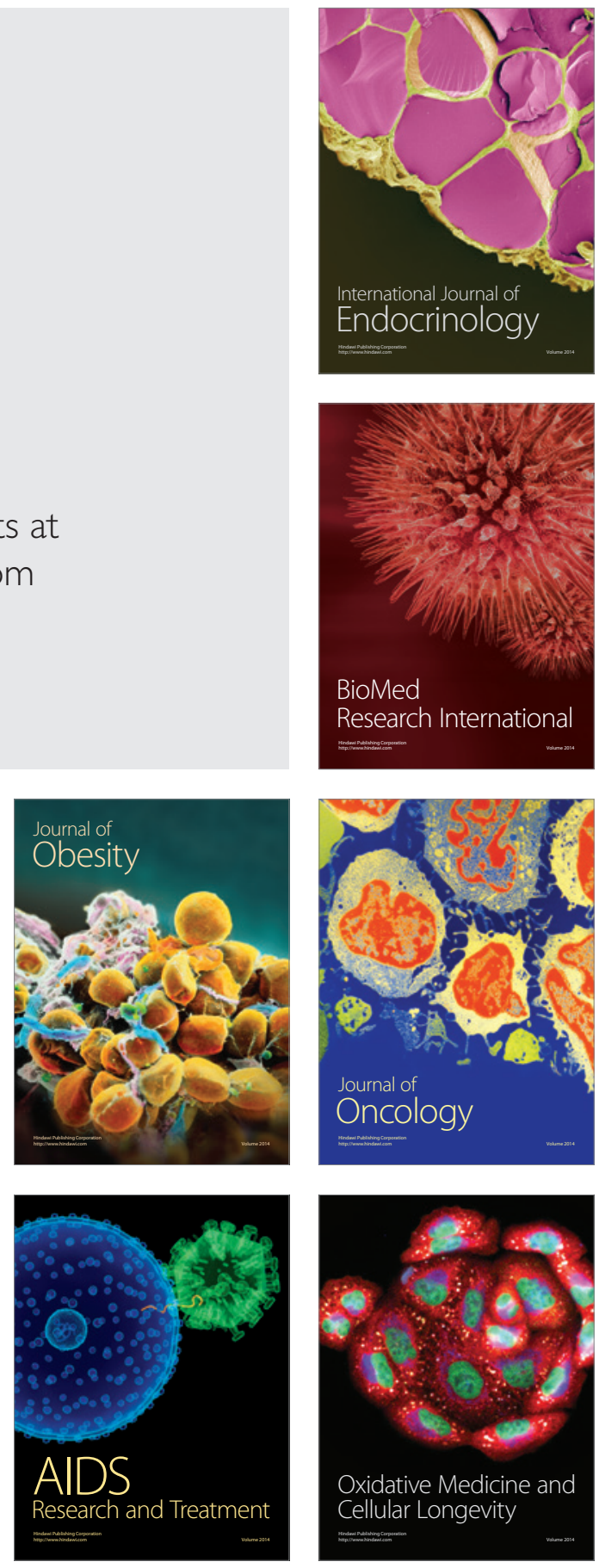